\title{
A review of the mechanical inerter: historical context, physical realisations and nonlinear applications
}

\author{
David J. Wagg(i)
}

Received: 27 November 2020 / Accepted: 10 February 2021 / Published online: 24 February 2021

(C) The Author(s) 2021

\begin{abstract}
In this paper, a review of the nonlinear aspects of the mechanical inerter will be presented. The historical context goes back to the development of isolators and absorbers in the first half of the twentieth century. Both mechanical and fluid-based nonlinear inerter devices were developed in the mid- and late twentieth century. However, interest in the inerter really accelerated in the early 2000 s following the work of Smith [87], who coined the term 'inerter' in the context of a force-current analogy between electrical and mechanical networks. Following the historical context, both fluid and mechanical inerter devices will be reviewed. Then, the application of nonlinear inerter-based isolators and absorbers is discussed. These include different types of nonlinear energy sinks, nonlinear inerter isolators and geometrically nonlinear inerter devices, many relying on concepts such as quasi-zero-stiffness springs. Finally, rocking structures with inerters attached are considered, before conclusions and some future directions for research are presented.
\end{abstract}

Keywords Nonlinear · Inerter $\cdot$ Mechanical

D. J. Wagg (凶)

Department of Mechanical Engineering, University of Sheffield, S1 3JD Sheffield, UK

e-mail: david.wagg@sheffield.ac.uk

\section{Introduction}

During the last 20 years, mechanical inerter devices have been the subject of substantial research interest in both academia and industry. These devices have been a major innovation in the research field of passive vibration control. They have also been primarily described in the literature in terms of linear vibration phenomena. However, as this field of research begins to mature, there is a growing recognition that nonlinearity plays a significant role in these devices. For example, most of the mechanisms used to realise mechanical inerter devices in practice are nonlinear, such as gears, ballscrew mechanisms and fluid flow. Furthermore, a number of research studies have been undertaken that are applying the inerter as nonlinear vibration mitigation methods.

This paper presents a review of the nonlinear dynamics aspects of the mechanical inerter-although to cover the historical context, a limited amount of linear dynamics is discussed as well. Inerters are often considered as vibration control devices, and this review will cover only passive devices. Semi-active and active control applications are not considered in detail, although they will be mentioned in the context of future developments—see also [2,14,36,38,59,99,122] and references therein for a selection of topics in these research fields.

The paper is structured as follows. In Sect. 2, the historical context and background of the mechanical inerter are presented. Then, in Sect. 3 physical reali- 
sations of mechanical inerter devices are considered in detail. Section 4 considers nonlinear applications of the mechanical inerter. Finally, in Sect. 5, conclusions and future directions for research are presented.

\section{History and background to the mechanical inerter}

In order to put the inerter into historical context, the first step is to consider the state-of-the-art methods in passive vibration control prior to the advent of inerterbased techniques.

The term 'inerter' was first introduced by Smith [87] using a force-current analogy between mechanical and electrical networks-see also [88]. In this context, the inerter is considered to represent the equivalent of the capacitor in electrical networks. As a result, in the mechanical domain, it has the property that the force generated is proportional to the relative acceleration between its end points (also called terminals, ports or nodes). The constant of proportionality for the inerter is called inertance and is measured in kilograms.

Long before this definition, engineers were seeking methods to reduce unwanted vibrations, particularly from resonances. We start by considering one of the earliest proposed solutions to this problem-see also Titurus [100] and Kuhnert et al. [51] for additional historical perspectives of the inerter.

\subsection{The tuned-mass-damper (TMD)}

In October 1909, Hermann Frahm filed a patent on a new device for 'damping vibrations of bodies' [27]. The idea was simple, and went on to radically improve many engineering applications where unwanted vibrations occurred. It was based on the observation that the resonance of an oscillating system could be reduced by deliberately attaching a smaller oscillator to the system. The key insight was that if the resonance frequency of the smaller device was designed in a particular way, then the two systems interfered with each so that the largest amplitudes of vibration were dramatically reduced.

The concept is shown in Fig. 1a, where the smaller oscillator-called the tuned-mass-damper (TMD)with mass $m_{a}$, damping $c_{a}$ and stiffness $k_{a}$ is shown attached to the primary (or host) system, with mass $M$ and stiffness $k$ (the primary system is assumed to have zero, or close to zero damping). The response of the primary system (without the TMD but with a small amount of damping) to a sinusoidal excitation is shown as a solid line in Fig. 1b, and a large displacement resonance peak can be seen. The response of the same system after the TMD, (also called a tuned-vibration-absorber and dynamic-vibration-absorber,) has been added is shown as a dashed line in Fig. 1b. It is clear that the idea proposed by Frahm leads to a dramatic reduction in maximum amplitude. Despite being over 100 years old, remarkably this idea was until very recently the state of the art in almost all relevant areas of engineering practice.

The idea was both popularised and given a rigorous design process by J.P. Den Hartog [20] and then J. E. Brock [11] since when it has been used extensively across all engineering (with some further refinements—see for example Liu and Liu [60] and references therein). Probably the most famous example is in the Taipei 101 in Taiwan. This is a $509 \mathrm{~m}$ high skyscraper, which between 2004 and 2008 was the tallest building in the world. Taipei suffers from typhoon storms and earthquakes, so the building was fitted with a tuned-mass-damper using a mass of 660 tonnes, as shown in Fig. 1c, d. The mass is suspended on cables and swings when the building is shaken by wind or earthquake. This swing motion is tuned to give the same cancellation effect of the largest vibrations based on Frahm's idea (see review by Gutierrez and Adeli [32] for a list of TMDs in tall buildings).

The tuned-mass-damper in the Taipei 101 has been shown to work amazingly well, but the fact that a 660tonne pendulum is required highlights one of the major drawbacks with the tuned-mass-damper idea. As the structure gets larger (or a greater damping effect is needed), then the mass required also becomes larger, which has several disadvantages, not least the cost and large space required inside the structure. Apart from having to use very large masses in large structures, the conventional TMD also suffers from two other important limitations. The first is that the sharp nature of the resonance peak (i.e. the solid line in Fig. 1b), means that small amounts of tuning error (for example from parameter changes over time) result in a rapid loss of performance. The second is that for systems with multiple resonances (which applies to very many real applications), the TMD can only suppress vibrations of one resonance peak. In fact, this is less of a problem in large 
(a)

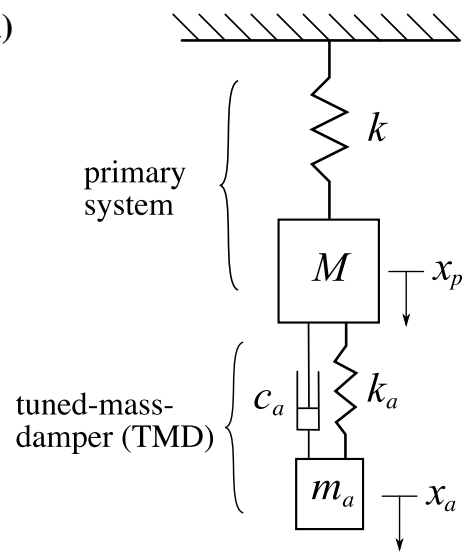

(c)

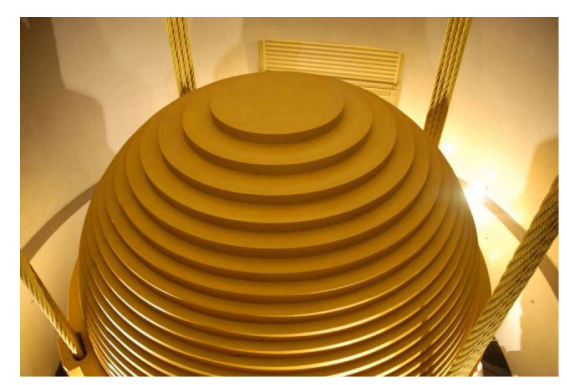

Fig. 1 The tuned-mass-damper (or tuned-vibration-absorber) showing a a schematic diagram of the primary system, $M, k$, with the absorber, $m_{a}, k_{a}, c_{a}$, attached. $\mathbf{b}$ A simulation of the (damped) primary system without the absorber attached (solid line) and tuned-mass-damper (dashed line) subjected to sinusoidal excitation $F \sin (\Omega t)$ where $F=1 \mathrm{~N}$. The frequency ratio is $\Omega / \omega_{p}$ where $\omega_{p}=\sqrt{k / M}$. The TMD was designed using the 'fixed point' method of Brock [11] (see also Den Hartog [20], and note that these are the 'fixed point' design rules that have been adapted for the design of inerter devices—see [37] and refer-

buildings, where typically $80 \%$ of the transverse vibration is from a single resonance, but is a major problem in other applications.

Two of these problems can be mitigated to a large extent by inerter-based devices. Firstly, an inerterbased device creates an inertial force that is significantly greater than its own mass. At the civil engineering scale, Sugimura et al. [92] described a system where the inertial force created was nearly 10000 times greater than the mass of the device. In addition, because an inerter is a relative motion device, it has an effect on all the resonances in the system, although it is typically still just one that is targeted in the design process. This and other effects are further described in Sect. 4.

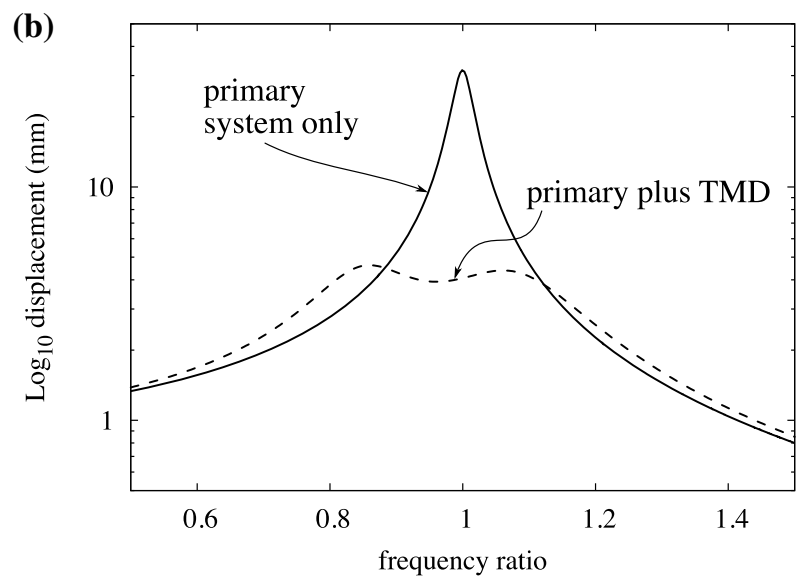

(d)

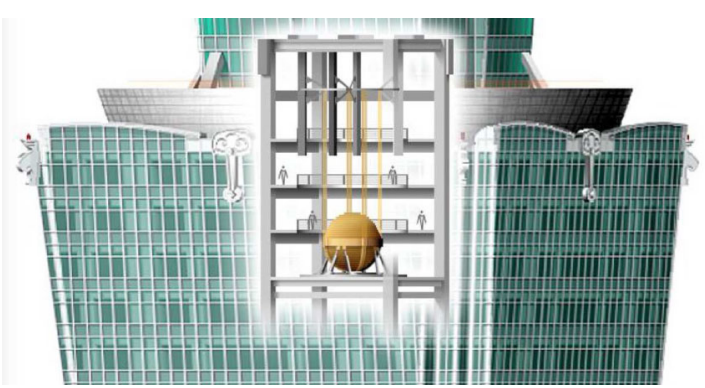

ences therein). Start with the given parameters of $k=1000 \mathrm{~N} / \mathrm{m}$, $M=100 \mathrm{~kg}, m_{a}=8 \mathrm{~kg}$ and $c=10 \mathrm{~kg} / \mathrm{s}$ (i.e. damping close to zero). Then, let $\mu=m_{a} / M$, so that $k_{a}=\frac{k \mu}{(1+\mu)^{2}}, \zeta=\sqrt{\frac{3 \mu}{(1+\mu)^{3}}}$ from which, $c_{a}=2 \zeta m_{a} \omega_{p}$, see for example Liu and Liu [60]. c A photograph of the 660-tonne mass from the Taipei 101 tunedmass-damper is shown. $\mathbf{d}$ The mass is suspended on cables, across four storeys at the top of the building, and the mass acts like a pendulum version of the TMD. A review of TMDs with a list of applications to buildings is reported in Gutierrez and Adeli [32]. Photograph credits: Guillaume Paumier

\subsection{The dynamic antiresonant vibration isolator (DAVI)}

During the early part of the twentieth century, the developing aerospace industry was concerned with issues related to control and stability, during which time several inerter like devices were developed - see for example the literature reviews given in $[51,100]$. Several of these novel devices will be discussed in this review, the first of which is a mechanical device called the dynamic antiresonant vibration isolator (DAVI), first patented in 1967 by Flannelly [25]. The antiresonance in the DAVI was exploited in the aerospace industry for applications including isolating the fuselage of a helicopter against 
(a)

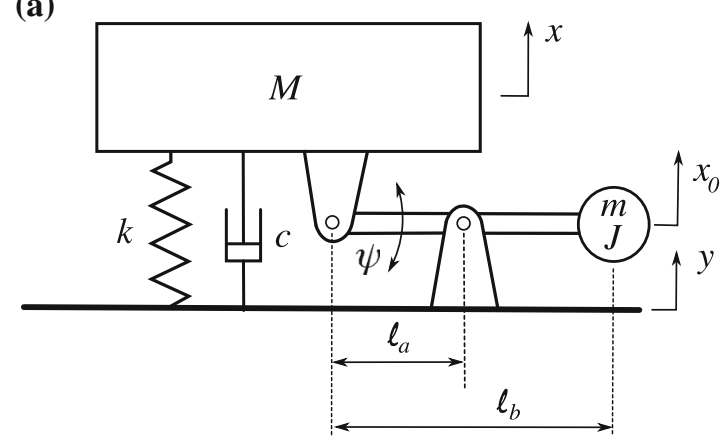

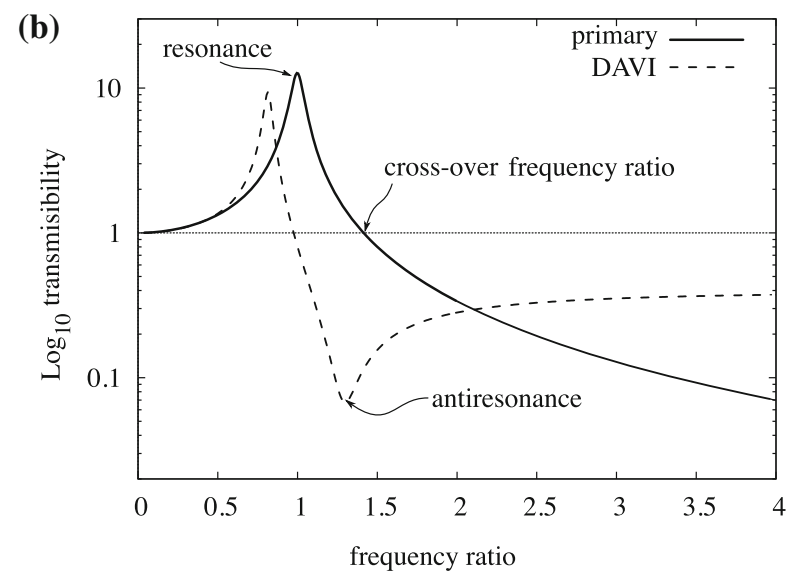

(c)

Fig. 2 The dynamic antiresonant vibration isolator (DAVI) showing a a schematic diagram of the primary system $(M, k$ and $c$ ) with the DAVI rod $\left(m, J, \ell_{a}\right.$ and $\left.\ell_{b}\right)$ attached. Note that the vertical displacement of the mass, $m$, is given by $x_{0}$ and the angular rotation of the DAVI rod is denoted by $\psi$. b A simulation of the primary system without the DAVI attached (solid line), and with the DAVI (dashed line) subjected to sinusoidal excitation $F \sin (\Omega t)$ where $F=1 \mathrm{~N}$. The frequency ratio is $\Omega / \omega_{p}$ where $\omega_{p}=\sqrt{k / M}$, and transmissibility is $|X / Y|$. The parameters are $k=80 \mathrm{~N} / \mathrm{m}, M=50 \mathrm{~kg}, m=10 \mathrm{~kg}, J=22.5 \mathrm{~kg} \mathrm{~m}^{2}, \ell_{a}=1 \mathrm{~m}$, $\ell_{b}=1.5 \mathrm{~m}$ and $c=5 \mathrm{~kg} / \mathrm{s}$ (i.e. damping close to zero). c The prototype DAVI Alpha, reproduced from [46] the vibration caused by its rotors, as described by Desjardins and Hooper [21].

It should be noted that the DAVI is a vibration isolator whereas the tuned-mass-damper, shown in Fig. 1, is a vibration absorber. An example of the DAVI concept is shown schematically in Fig. 2a, where the objective is to isolate the mass $M$ from the support input $y$.

Although the DAVI system shown in Fig. 2a contains geometric nonlinearities, to the authors knowledge there has not been any research on the nonlinear version of this system. Instead, we present the linearised version which is related to the original derivations that can be found in Anderson and Smith [3] and Jones [46], see also [7, 10,21,23,62,119].

In order to derive a transmissibility relationship $(\max (x) / \max (y)$ as frequency is varied) for the DAVI system shown in Fig. 2a, it is required to derive the equations of motion in terms of just $x$ and $y$. Therefore, to eliminate $x_{0}$ and $\psi$ the following relationships are used $x_{0}=\alpha y-(\alpha-1) x$, where $\alpha=\ell_{b} / \ell_{a}$, and

$\sin (\psi)=\frac{y-x}{\ell_{a}} \approx \psi \rightsquigarrow \ddot{\psi} \approx \frac{\ddot{y}-\ddot{x}}{\ell_{a}}$

which restricts the subsequent analysis to small angle ranges for $\psi$. Note also that $\ell_{a}$ and $\ell_{b}$ must be chosen so that $\alpha>1$.

Considering the equilibrium of mass $M$ and the DAVI rod gives

$$
\begin{gathered}
M \ddot{x}+c(\dot{x}-\dot{y})+k(x-y)+F_{p}=0, \text { and } \\
F_{p}=\frac{1}{\ell_{a}}\left[-m \ddot{x}_{0}\left(\ell_{b}-\ell_{a}\right)-J \ddot{\psi}\right],
\end{gathered}
$$


where $F_{p}$ is the force on the pivot point attached to $M$. Substituting for $x_{0}$ and $\ddot{\psi}$ using the expressions above leads to an equation of motion of

$$
\begin{aligned}
& {\left[M+m(\alpha-1)^{2}+\frac{J}{\ell_{a}^{2}}\right] \ddot{x}} \\
& +c \dot{x}+k x=\left[m \alpha(\alpha-1)+\frac{J}{\ell_{a}^{2}}\right] \ddot{y}+c \dot{y}+k y, \rightsquigarrow \\
& \left(M+b_{1}\right) \ddot{x}+c \dot{x}+k x=b_{2} \ddot{y}+c \dot{y}+k y,
\end{aligned}
$$

where $b_{1}=m(\alpha-1)^{2}+\frac{J}{\ell_{a}^{2}}$ and $b_{2}=m \alpha(\alpha-1)+\frac{J}{\ell_{a}^{2}}$ are the inertance values for the DAVI in units of kilograms. It can be seen that by adjusting the parameters of the DAVI, namely $m, J, \ell_{a}$ and $\ell_{b}$, the level of inertance generated can be defined. This is an important property of an inerter device that allows the vibration mitigation strategy to be relatively easily designed.

Making the idealised assumption that the bar of the DAVI has no mass such that $J=m \ell_{b}^{2}$ leads to inertance values of $b_{1}=m\left((\alpha-1)^{2}+\alpha^{2}\right)$ and $b_{2}=m \alpha(2 \alpha-1)$ and a governing equation given by

$$
\begin{aligned}
& {\left[M+m\left((\alpha-1)^{2}+\alpha^{2}\right)\right] \ddot{x}+c \dot{x}+k x} \\
& \quad=m \alpha(2 \alpha-1) \ddot{y}+c \dot{y}+k y .
\end{aligned}
$$

This is the governing equation used to compute the results shown in Fig. $2 b$.

Results for the isolator are expressed in terms of the transmissibility, $\max (x)$ divided by $\max (y)$ for each frequency value across the range considered. Now assuming that the input $y$ and response $x$ are both sinusoidal, then Eq. (3) leads to an undamped (i.e. by setting $c=0$ ) transmissibility relationship of

$$
\frac{X}{Y}=\frac{k-b_{2} \Omega^{2}}{k-\left(M+b_{1}\right) \Omega^{2}}
$$

where $X$ and $Y$ are the displacement amplitudes of sinusoidal $x$ and $y$ signals, respectively, and $\Omega$ is the frequency of the sinusoidal support motion. For this undamped DAVI system, there are two important frequency values

$$
\omega_{a}=\sqrt{\frac{k}{b_{2}}} \text { and } \omega_{r}=\sqrt{\frac{k}{M+b_{1}}}
$$

where $\omega_{a}$ is the frequency where the antiresonance occurs (the zero of (5)), and $\omega_{r}$ is the resonance frequency of the isolated system (the positive pole of (5)).

The damped transmissibility function becomes

$$
\begin{aligned}
\frac{X}{Y} & =\frac{k-b_{2} \Omega^{2}+\mathrm{i} c \Omega}{k-\left(M+b_{1}\right) \Omega^{2}+\mathrm{i} c \Omega} \\
& \rightsquigarrow\left|\frac{X}{Y}\right|=\sqrt{\frac{\left(1-\mu_{2} \hat{\omega}^{2}\right)^{2}+(2 \zeta \hat{\omega})^{2}}{\left(1-\left(1+\mu_{1}\right) \hat{\omega}^{2}\right)^{2}+(2 \zeta \hat{\omega})^{2}}}
\end{aligned}
$$

where $c$ is the viscous damping coefficient, $\mu_{1}=b_{1} / M$ and $\mu_{2}=b_{2} / M$ are the inertance to mass ratios, $\hat{\omega}=\Omega / \omega_{p}$ is the frequency ratio, $\zeta=c / 2 M \omega_{p}$ is the damping ratio, and $\omega_{p}=\sqrt{k / M}$ is the undamped natural frequency of the primary system.

The response of the primary system without the DAVI is shown as the solid line in Fig. 2b. The crossover frequency ratio is the value where the transmissibility equals one (for nonzero frequency ratio values). To the left of the cross-over frequency is the amplification region (meaning $|X / Y|>1$ ) and to the right of the cross-over frequency is the attenuation region (meaning $|X / Y|<1$ ). This can be compared to the primary system with DAVI, computed using Eq. (7), and shown as the dashed line in Fig. 2b. Note that, now the DAVI has been added, the transmissibility plot has both a resonance and an antiresonance peak.

The DAVI response (dashed line) in Fig. $2 \mathrm{~b}$ does three important things: (i) reduces the height of the resonance peak, (ii) moves the cross-over frequency to the left, which reduces the amplification region, and (iii) creates an antiresonance, where the amplitudes of response are dramatically reduced. In terms of the level of reduction at the antiresonance, it can be seen for the example in Fig. 2b that there are approximately two orders of magnitude between resonance peak and antiresonance (in the idealised case, when $c=0$ transmissibility is zero at the antiresonance). If the operating point of the primary system can be moved close to the antiresonance, then large reductions in vibration transmission can be achieved, and this is a common approach in applications - see Jones [46] for a detailed design methodology.

Although there have been more recent applications of the DAVI (e.g. Liu et al. [62]), the concept was not used extensively following the initial development. However, the DAVI did help as a design model for other vibration isolation problems. In particular, the ability to 
introduce an antiresonance was important as a design possibility for passive vibration isolation. As a result, the DAVI-type model has subsequently been used for other vibration isolation devices. For example, it has been used to develop certain types of automotive engine mounts that are a type of fluid inerter. This, and other mechanical inerter devices, will be discussed in the next section.

More recently, inerter isolation devices with spring, damper and inerter in parallel have been studied extensively-see [37] for an analysis of the parallel inerter isolator case. It is interesting to note that the transmissibility expressions found for the DAVI in Equation (7) are equivalent to those for the parallel inerter isolator case if it is assumed that $\mu_{1} \approx \mu_{2}$. This type of parallel inerter isolator can be realised in practice using a flywheel inerter, as will be described in more detail in Sect. 3.2.

\section{Mechanical inerter devices}

\subsection{Fluid inerter devices}

\subsubsection{The hydramount}

An alternative to generating inertial forces using a lever mechanism, such as the DAVI, is to use fluid flow within a chamber or pipe. This concept was developed extensively in the twentieth century for aerospace and automotive applications, and led to a wide range of devices generally referred to as 'shock absorbers' and 'isolation mounts' amongst other terminology. A more detailed historical review of fluid-based devices is given by Titurus [100]. One example, relevant to this review was a fluid inerter that was incorporated into an automotive engine mount, called the 'hydraulic mount' or sometimes 'hydramount' - see Flower [26] and references therein.

Vibration isolation mounts of this type had long been based on a rubber element that acted as a combined 'spring' and 'damper' - see for example Rivin [77]. Although rubber used in this way has nonlinear restoring force and damping properties, many designs assume a linear model, typically like the parallel spring $k$ and damper $c$ of the system shown in Fig. 3a without the hydramount. As a result, the design objective of such a linear isolator is to reduce the resonance peak, and move the cross-over frequency to the left. One way this can be achieved is by reducing the stiffness, and (if possible) increasing the damping.

An example is shown in Fig. 3b) where the response of the primary system, with parameters $M, c, k$, is plotted as the solid line. The dot-dashed line in Fig. 3b) shows the response of a linear isolator, where the stiffness, $k_{I}$ is less than the primary stiffness, $k$. In addition, the damping of the linear isolator is greater than the primary system, $c_{I}>c$, and it can be seen that the height of the resonance peak is reduced. Furthermore, the cross-over frequency has moved to the left, therefore increasing the attenuation region, when compared to the primary system curve (solid line).

However, reducing the stiffness is often undesirable (or impossible) in many practical applications, as the primary mass needs to be supported without excessive static deflection. Therefore, it is often preferable to seek alternatives where the stiffness of the primary system does not need to be reduced. From Equation (6) (assuming the DAVI-type model is appropriate), it can be seen that the natural frequency of the system, $\omega_{r}$ can be reduced by increasing the inertance, without needing to change either the mass or linear stiffness values.

The hydramount was designed to improve the performance of a linear mount by introducing inertance using hydraulic fluid that is forced between two chambers via a helical pipe (also called an annulus or 'inertia track'), as shown schematically in Fig. 3a. As the fluid rotates around the helical pipe, $H$, it creates a 'fluid flywheel' effect that can be designed to give an antiresonance in a similar way to the DAVI. In fact, Flower [26], proposed a design process that used the DAVI lever arm model, very similar to that shown in Fig. 2a, in order to approximate the effect of a rotating fluid inside the mount, and this approach has been used to compute the hydramount response (dashed line) shown in Fig. 3b. As a result, the hydramount can create an antiresonance, and this can be designed to be very close to the operating frequency range of the system such that the isolation effect is maximised.

Note that away from the antiresonance, for example at frequency ratios above 2, the hydramount (and DAVI in the previous example) are worse than the linear case. This demonstrates why the frequency of operation needs to be close to the antiresonance in order to work effectively. More recent studies of the hydramount are given by Singh [86], Golnaraghi and Nakhaie [30] and Soltani et al. [91]. 
(a)

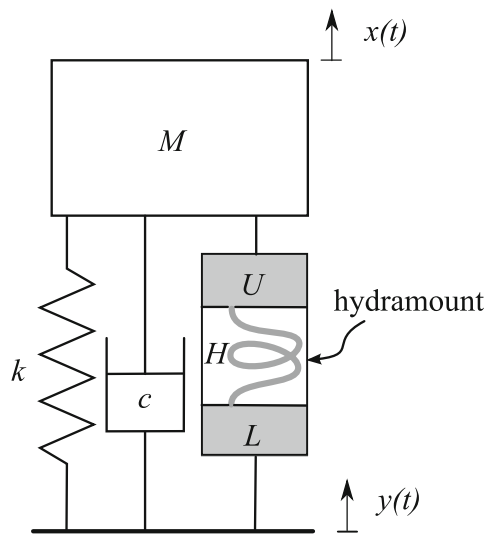

(c)

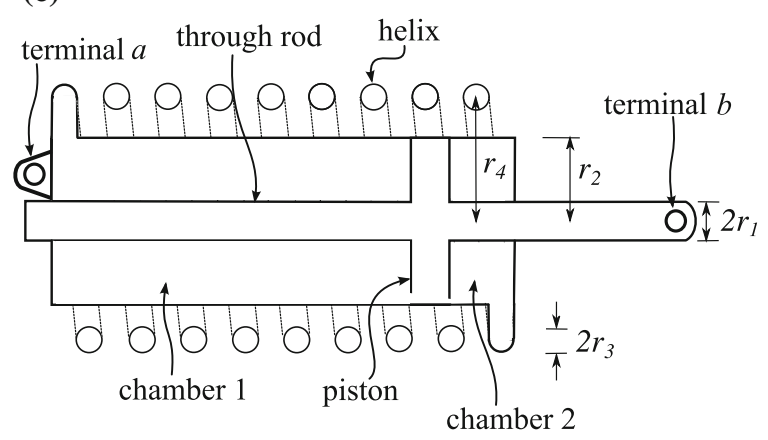

Fig. 3 Fluid inerter concept, showing a a schematic diagram of the hydramount system, where engine mass, $M$, is to be isolated from chassis input $y(t)$. The rubber mount is assumed to be a linear (i.e. $k$ and $c$ ) with the fluid inerter consisting of hydraulic fluid that is passed between an upper, $U$, and lower, $L$, chamber via a helical pipe $H$. b a simulation of the primary system ( $M, k, c$ solid line), linear isolator $\left(M, k_{I}, c_{I}\right.$ dot-dash line) and hydramount (dashed line, computed using a DAVI model) subjected to sinusoidal excitation $F \sin (\Omega t)$ where $F=1 \mathrm{~N}$. The frequency ratio is $\Omega / \omega_{p}$ where $\omega_{p}=\sqrt{k / M}$, and transmissibility is $|X / Y|$. The parameters are $k=80 \mathrm{~N} / \mathrm{m}, k_{I}=60 \mathrm{~N} / \mathrm{m}$, $M=50 \mathrm{~kg}, m=10 \mathrm{~kg}, J=22.5 \mathrm{kgm}^{2}, \ell_{a}=1, \ell_{b}=1.5$, $c=5 \mathrm{~kg} / \mathrm{s}$ and $c_{I}=10 \mathrm{~kg} / \mathrm{s}$. c Schematic cross-sectional diagram

\subsubsection{The helical fluid inerter}

Helical tubes of fluid had been proposed as useful components in dampers a considerable time before the development of the hydramount — see for example O'Connor [71]. A more detailed historical description and comprehensive literature reviews can be found in

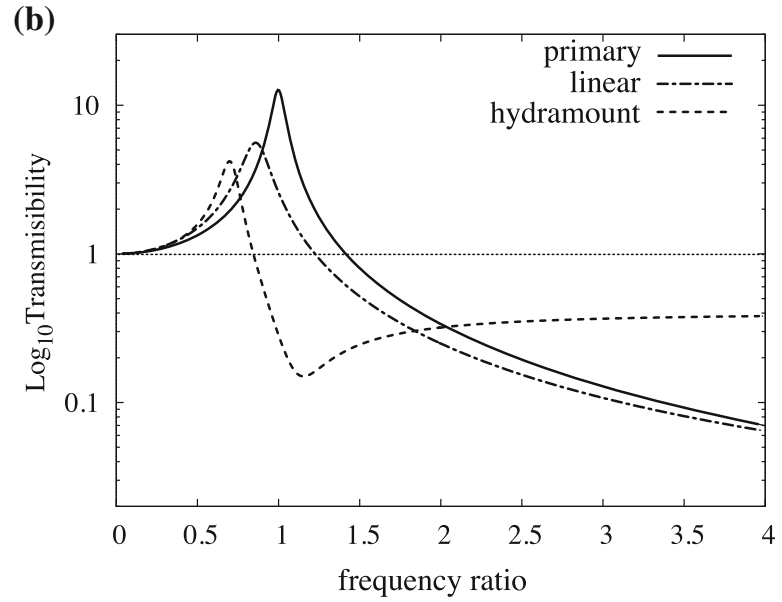

(d)

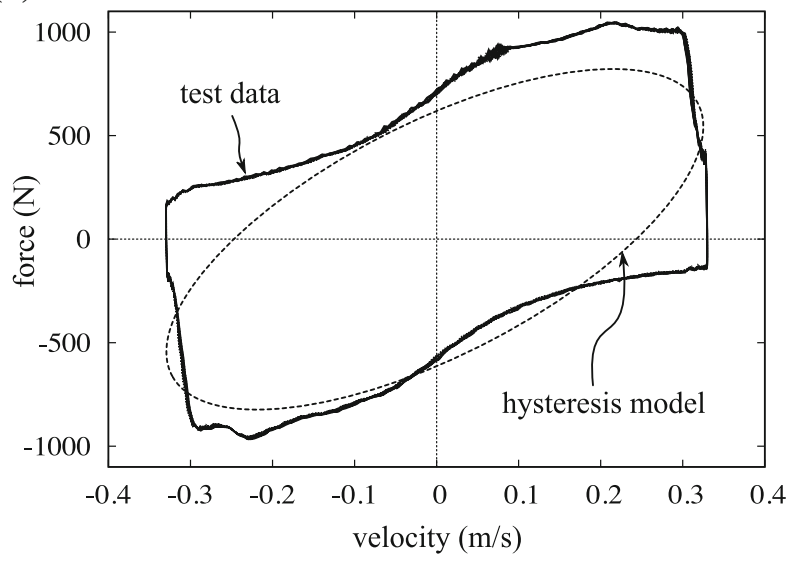

of helical fluid inerter. $\mathbf{d}$ A comparison of a helical fluid inerter test results from Smith and Wagg [90] and a linear hysteretic model based on the force in the fluid inerter being approximated as $F_{h}=b_{h} \ddot{z}+c_{h} \dot{z}$, where $b_{h}$ is the inertance, $c_{h}$ is the additional viscous damping within the fluid inerter and $z=x-y$ is the relative displacement across the terminals of the inerter device (terminals are shown as $a$ and $b$ in (c)). When sinusoidal inputs are assumed, $F_{h}=c_{h} \dot{z} \pm b_{h} \Omega \sqrt{\Omega^{2} Z^{2}-\dot{z}^{2}}$, where $Z$ is the maximum amplitude of the sine wave with frequency $\Omega$. This forms an ellipse, which is shown as a dotted line in (d). The identified parameters for the model are close to the previously estimated values from Smith and Wagg [90], and were given by $b_{h}=98.4$ $\mathrm{kg}$ and $c_{h}=1628 \mathrm{~kg} / \mathrm{s}$

Rivin [77] and Titurus [100]. The first known application of a fluid inerter device is the 'mass pump' developed by Kawamata [47-49] starting in the 1970s. However, interest in helical fluid-filled tubes used as inerters only really gained significant momentum following the work of Swift et al. [94]. 
In contrast to a hydramount, a helical fluid inerter is not typically integrated into the mount. The most common practical realisation is a fluid (usually hydraulic oil) filled cylinder with a helical tube wrapped around the outside, as shown schematically in Fig. 3c. The radius of the main fluid chamber is given by $r_{2}$, and the piston through rod which pushes the fluid inside the main chamber has radius $r_{1}$. The distance $r_{4}$ is the helix radius from the centre of the longitudinal axis of the cylinder and $r_{3}$ is the inner radius of the helical pipe.

The cross-sectional area of the cylinder is $A_{1}=$ $\pi\left(r_{2}^{2}-r_{1}^{2}\right)$ and the cross-sectional area of the helix is $A_{2}=\pi r_{3}^{2}$. The principal of conservation of mass is normally applied to derive an expression equating a linear (relative) displacement in the cylinder, $z=x-y$ to an angular displacement of a fluid element in the helix, $\theta$. Taking the mass of the fluid in the helix as $m_{h e l} \approx \rho_{f} L_{h} A_{2}$, where $\rho_{f}$ is the mass density of the fluid at reference temperature and $L_{h}$ is the length of the helix, then the moment of inertia about the axis of the piston is defined as $J=m_{h e l} r_{4}^{2}$. Making a series of assumptions about the ideal nature of the device (see for example Swift et al. [94]) leads to the idealised relationship for the equivalence of kinetic energy in the inerter

$\frac{1}{2} b_{h e l} \dot{z}^{2}=\frac{1}{2} J \dot{\theta}^{2}$

where $\theta$ is the rotation angle of the fluid in the helix, $\dot{z}$ is the relative velocity between the end points of the inerter, and $b_{h e l}$ is the inertance of the fluid in the helix. These definitions can be used to derive the following expression [28]

$b_{h e l}=\frac{m_{h e l}}{\left(1+\left(h /\left(2 \pi r_{4}\right)\right)^{2}\right)}\left(\frac{A_{1}}{A_{2}}\right)^{2}$,

where $h$ is the pitch of the helix. As a result, $b_{h e l}$ can be designed using the geometry of the cylinder and helix using Equation (9).

Fluid inerters have a significant level of inherent damping due to the fluid dynamic effects. This leads to nonlinear relationships in terms of the velocity, in addition to which, the friction effects of the piston are significant and also nonlinear in nature. In general, the forces between terminals $a$ and $b$ of the helical fluid inerter shown in Fig. 3c are modelled using

$f_{\text {total }}=f_{\text {inertial }}+f_{\text {damping }}+f_{\text {friction }}$

where it is noted that entry and exit losses between the cylinder and the helix tend to be neglected as they're (usually) small compared to the other effects-see for example discussions in $[15,63,82,83,94]$. In terms of capturing the physical behaviour, both damping and frictional effects will be nonlinear.

For example, an expression using nonlinear fluid damping combined with a Coulomb-type friction model leads to a force expression of

$f_{\text {total }}=b_{\text {hel }} \ddot{z}+c_{d} \dot{z}^{\beta}+f_{0} \operatorname{sgn}(z), \quad$ with $\quad z=x-y$

where $c_{d}$ is the nonlinear damping coefficient, $f_{0}$ is the static friction coefficient, and $\beta=1.75$ is the nonlinear damping exponent. This derivation (see for example De Domenico et al. [15]) assumes turbulent flow and a smooth pipe, so that the nonlinear damping coefficient can be approximated as

$c_{d}=0.664 \mu_{f}^{0.25} \rho_{f}^{0.75} \frac{L_{h} A_{1}}{r_{3}^{1.25}}\left(\frac{A_{1}}{A_{2}}\right)^{1.75}$

where $\mu_{f}$ is the dynamic viscosity of the fluid. Specific other examples can be found in $[63,64,82,83,94]$, where other choices for $\beta$ such as $\beta=2$ are discussed.

As discussed for the DAVI and hydramount examples, inerters are used in combination with other elements, such as masses, springs and dampers, in order to create vibration absorbers or isolators. This presents two problems for fluid inerters; (i) the tuning rules for isolators and absorbers (e.g. [37]) are linear, and so do not translate to nonlinear systems, and (ii) there is a strong coupling between the inertance and damping (i.e. see Equations (9) and (12)) making it very difficult to design and specify separate inertance and damping values.

One approach used by De Domenico et al. [15] for earthquake excitation was to apply statistical linearisation (for an introduction to this topic, see Roberts and Spanos [78]) which then resulted in a constrained optimisation problem to find the optimal values of $b_{h e l}$ and $c_{d}$ (friction was neglected, on the basis that for 
(a)

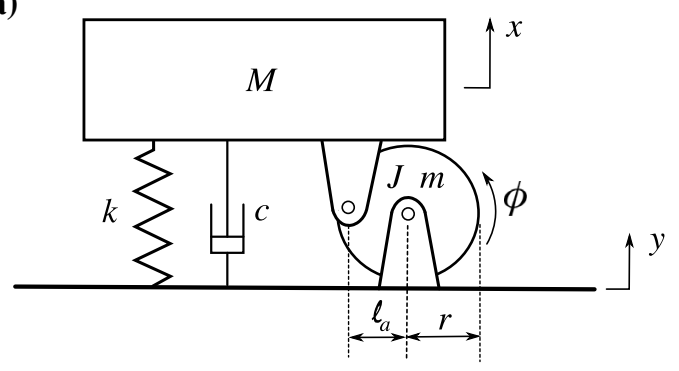

(c)

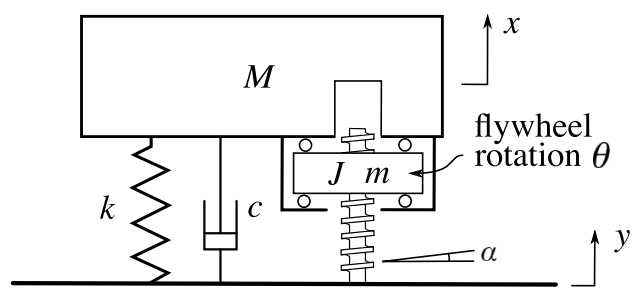

(b)

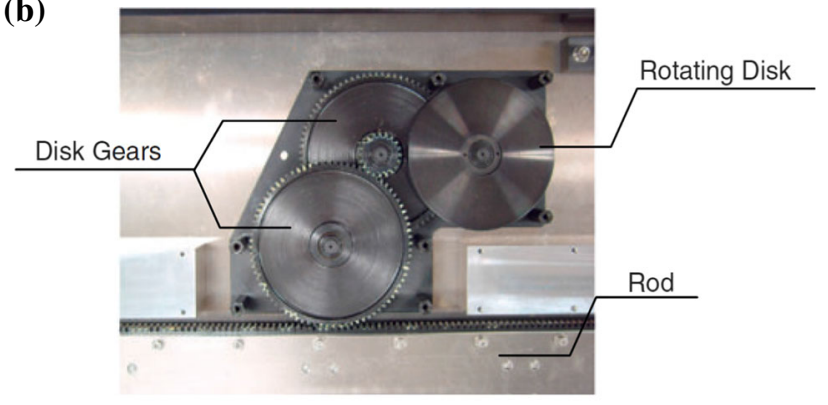

(d)

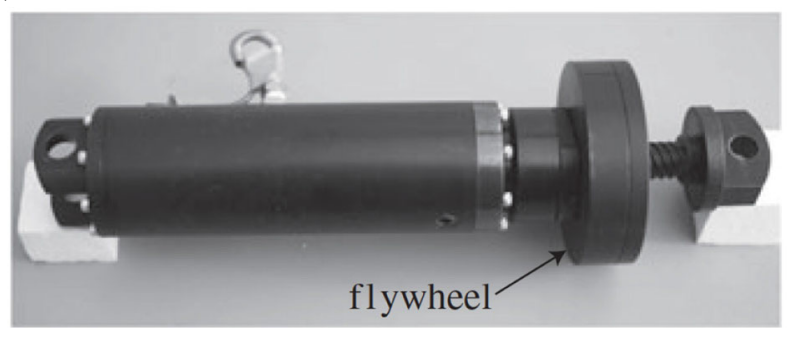

gears to amplify the flywheel effect. c A flywheel-driven 'ballscrew' inerter, with flywheel parameters $J, m$. d A viscous mass damper [41], which consists of a ball-screw inerter in combination with viscous oil damping

and Pei [101], and then friction as well by Zhang et al. [124]. These studies also included some comparison between mem- and nonlinear models for the inerter, an idea that was also considered by Biolek et al. $[8,9]$ in the context of higher-order electrical elements.

In the next section, we consider a final class of inerters to be discussed in this review, those that use rotational flywheel effects to create inertance.

\subsection{Mechanical flywheel inerters}

\subsubsection{Pivoted flywheel and Rack-and-pinion inerters}

The flywheel is an ancient technology that has been used in applications throughout human history as described by White $\operatorname{Jr}$ [116]. One of the main benefits of a flywheel is its simplicity. For example, the lever arm design of the DAVI, shown in Fig. 2 has an asymmetry which leads to two inertance values, given in Eq. (3). This asymmetry is removed if the lever and mass are replaced with a flywheel, to create a pivoted flywheel inerter, as shown schematically in Fig. 4a. Note that to fully eliminate the asymmetry, the pivots would need 
to be equally spaced from the centre of the flywheel, however the design with one pivot offset and one close to the centre has been found easier to implement from a practical perspective - see for example John and Wagg [45] — and it is also a sufficiently close approximation for small angles of rotation.

For the system in Fig. 4a, the flywheel is assumed to produce a couple equal to $F \ell_{a}$, where $F$ is the force on each of the pivots (which are assumed to be massless). The couple can be directly related to the torque, $T$, and the angular acceleration via

$T=F \ell_{a}=J \ddot{\phi}$

where $J$ is the moment of inertia of the flywheel, $\phi$ is the angle of rotation and an overdot represents differentiation with respect to time, $t$. Using the same approximation for small angles as in Eq. (1) (i.e. with $\phi$ instead of $\psi$ ) gives

$F=b_{p}(\ddot{y}-\ddot{x})$,

where the inertance, $b_{p}$, is defined as

$b_{p}=\frac{J}{\ell_{a}^{2}}$.

Note that, unlike the DAVI, there is now only a single inertance value, $b_{p}$, given by Eq. (15). Furthermore, $b_{p}$ has only two parameters, the moment of inertia $J=$ $\frac{m r^{2}}{2}$, and the lever arm distance $\ell_{a}$ as given in Equation (15)

Using the above relationships, the equation of motion for the pivoted flywheel inerter system shown in Fig. 4a is

$$
M \ddot{x}+k(x-y)+c(\dot{x}-\dot{y})+b_{p}(\ddot{x}-\ddot{y})=0,
$$

where $c$ is the viscous damping parameter. Equation 16 is the simplest model for an inerter isolator system, and as a result it has been widely used to approximate a range of devices in the literature-see for example the discussion in Hu et al. [37] and other references therein. As a result of there being just a single inertance value, the damped transmissibility function for Equation (16) becomes

$$
\frac{X}{Y}=\frac{k-b_{p} \Omega^{2}+\mathrm{i} c \Omega}{k-\left(M+b_{p}\right) \Omega^{2}+\mathrm{i} c \Omega} \rightsquigarrow
$$

$$
\left|\frac{X}{Y}\right|=\sqrt{\frac{\left(1-\mu_{p} \hat{\omega}^{2}\right)^{2}+(2 \zeta \hat{\omega})^{2}}{\left(1-\left(1+\mu_{p}\right) \hat{\omega}^{2}\right)^{2}+(2 \zeta \hat{\omega})^{2}}}
$$

where $\mu_{p}=b_{p} / M$ and all other parameters are the same as previously defined in Eq. (7).

One of the earliest inerter devices of this type is the so-called gyro-mass which was patented in 1997 by Okumura [72]. This device used a rack-and-pinion gear system in order to amplify the effect of the flywheel, and a related device is shown as an example in Fig. $4 \mathrm{~b}$ from Saitoh [79]. Another early example of the rack-andpinion inerter concept was discussed by Smith [87] and physical realisations of rack-and-pinion devices that have been tested experimentally are given by Smith and Wang [89], Papageorgiou et al. [73], Saitoh [79] and Madhamshetty and Manimala [66]. When gears are used, the inertance relationship will become

$b_{p} \propto \frac{J}{\ell_{a}^{2}}$,

where the proportionality is related to gear ratios, as for example described by $[67,79,87,97]$.

\subsubsection{Ball-screw inerters}

In Fig. 4c, a schematic diagram of an inerter system is shown where the flywheel rotation occurs in the horizontal plane. The flywheel rotation, $\theta$, is driven by the relative motion of the device in the vertical plane. These types of inerters are generally referred to as ball-screw inerters, and a derivation and some historical context are given by Rivin [77]. For the system in Fig. 4c, the torque, $T$, is now related to the vertical force, $F$, generated by the flywheel by assuming it acts like a nut, so that

$$
\begin{aligned}
T & =F r_{m} \tan (\alpha \pm \gamma) \rightsquigarrow \quad F=\frac{T}{r_{m} \tan (\alpha \pm \gamma)} \\
& =\frac{J \ddot{\theta}}{r_{m} \tan (\alpha \pm \gamma)}
\end{aligned}
$$

where $r_{m}$ is the mean radius of the thread (meaning the radius to the centre of the contact region), $\theta$ is the rotation of the flywheel, $\alpha$ is the helix angle of the thread, and $\gamma=\arctan \left(\mu_{\text {fric }}\right)$ is the friction angle, where $\mu_{\text {fric }}$ is the friction coefficient. The plus or minus in front of $\gamma$ defines the two cases of the flywheel moving up and down (note we are neglecting the mass of the screw rod and flywheel housing, plus the gravitational 
contribution from the mass of the flywheel, all of which should be small compared to the inertance).

Then, from the geometry of the helix, it can be shown that $\theta=\frac{y-x}{r_{m} \tan \alpha}$ such that the vertical force within the nut (i.e. flywheel and threaded rod) becomes

$$
F=\frac{J(\ddot{y}-\ddot{x})}{r_{m}^{2} \tan (\alpha \pm \gamma) \tan \alpha}
$$

which is a similar relationship to Eq. (14), and we write it as

$$
F=b_{s}(\ddot{y}-\ddot{x}), \quad \text { with } \quad b_{s}=\frac{J}{r_{m}^{2} \tan (\alpha \pm \gamma) \tan \alpha} .
$$

where $b_{s}$ is the inertance of the ball-screw. The equation of motion for the system in Fig. $4 \mathrm{c}$ is the same as Eq. (16) with $b_{s}$ instead of $b_{p}$.

In the idealised case where friction is assumed to be zero (i.e. $\mu_{\text {fric }}=0$ ), then we can use the relationship between the pitch of the thread, $p$, and the helix angle given by $\tan \alpha=\frac{p}{2 \pi r_{m}}$ to simplify Eq. (21) so that the inertance becomes

$b_{s}=\frac{4 \pi^{2} J}{p^{2}} \rightsquigarrow b_{s}=\left(\frac{2 \pi \kappa}{p}\right)^{2} M$ for $\mu=0$

where $\kappa$ is the radius of gyration from the relationship $J=M \kappa^{2}$-see for example the derivation in Smith [88].

Although is possible in theory to have a dry-friction ball-screw device, in practice they need to be lubricated. In many designs, the fluid provides both lubrication and viscous damping as well. This has been a particular area of development for civil engineering applications. The combination of a ball-screw device with viscous fluid damping was proposed by Arakaki $[4,5]$ to create the rotary damping tube. This concept was refined by subsequent researchers such as Sugimura et al. [92] and Ikago et al. [41] and is now known as the viscous mass damper. The example shown in Fig. $4 \mathrm{~d}$ is reproduced from Ikago et al. [41]. In the civil engineering domain, forces are very large. For example, the viscous mass damper used in Sugimura et al. [92] had a mass of $560 \mathrm{~kg}$ and was able to create an inertance of 5400 tonnes, whilst the viscous damping was $7300 \mathrm{kNs} / \mathrm{m}$.

In terms of the nonlinearities that can occur in ballscrew inerters, Wang and Su [107] and Papageorgiou et al. [73] described the friction and backlash effects that can occur. Both proposed backlash models, and a method for identifying the parameters of the system (see also Brzeski and Perlikowski [12] for a related discussion). As the system had little viscous damping, the authors were able to use a model similar to Eq. (10) with $f_{\text {damping }} \approx 0$ assumed. Another study that was close to the dry-friction ball-screw case was carried out by Gonzalez-Buelga et al. [31] who used a commercially manufactured Penske inerter device with most of the damping oil drained out of it. As a result, the authors were able to use a similar modelling approach, by assuming the device is dominated by inertance and friction forces. These studies relate strongly to automotive examples which are another large domain of application for ball-screw inerters (i.e. Penske manufactures inerter devices for this market). For further discussion of this topic, with reference to the nonlinear effects, see for example Wang et al. [109], Sun et al. [93] and Shen et al. [82,83].

There are some other mechanical inerter devices that have been proposed that include gears. Two such examples are the rotational inerter, based on a realisation using an epicyclic gearbox, and the gear-pump inerter which combines fluid flow and gears-see [88] and references therein for a discussion of both these systems. However, for the purposes of this current review, we now consider the topic of inerter applications that make use of nonlinearity.

\section{Nonlinear applications of the inerter}

The nonlinearities described in the mechanical inerter devices in Sect. 3 are significant at the scale of the devices, but become less significant when used in a larger scale system in combination with other (nominally) linear elements such as springs and dampers. For example, when the viscous mass damper, shown in Fig. 4d, is combined with other elements it can be tuned to give a vibration absorber effect and therefore becomes a tuned-viscous-mass-damper (TVMD) (see Ikago et al.[41], and note that this device is also sometimes called the parallel-connected-viscousinerter-damper (PVID)). The absorber tuning can be done using a linear tuning approach adapted from the tuned-mass-damper described in Sect. 2.1 (see also Fig. 2.1). 
Also using linear theory, and varying the arrangement of elements has led to other inerter-based absorbers. Most notably, the tuned-inerter-damper (TID) was proposed by Lazar et al. [53], and the tuned-massdamper-inerter (TMDI) proposed by Marian and Giaralis [69]. A wider analysis of other configurations can be found in $\mathrm{Hu}$ et al. [37] and Krenk [50]. These three systems (i.e. TVMD, TID and TMDI) and variants have been studied extensively for a range of applications including vehicle suspensions and steering systems $[24,38,52,59,73,82,83,89,93$, $102,109,120]$, train suspension systems [57,104-106], and civil engineering systems - see for example [15, $16,18,29,33,34,39,53,54,74,84,85,96,103,121]$ and references therein. It is also worthy of note that the TVMD, TID and TMDI have been used to largely mitigate the limitations of the TMD described at the end of Sect. 2.1, although only a small number of concepts have been deployed in real engineering applications.

The majority of these studies assume the systems are linear. However, the relevance of these applications should become apparent as we resume the review of nonlinear inerter applications.

\subsection{Nonlinear energy sink inerter devices}

Several studies have been carried out to investigate the potential benefits of using nonlinearity to create nonlinear vibration absorbers. One way to do this is to use nonlinear springs instead of linear springs in the inerter-based devices. The resulting oscillator systems are closely aligned to the concept of a nonlinear energy sink (NES, see the recent review by Ding and Chen [22]), which in simple terms can be considered to be analogous to the tuned-mass-damped system shown in Fig. 1a where the spring, $k_{a}$ is replaced with a nonlinear spring.

Devices that fall into the category of being nonlinear energy sink inerter devices are often abbreviated by NESI. This can include devices with different types of layout and different types of nonlinear spring. In order to distinguish between different devices, we use an additional classification. For example, in terms of system layout, using a cubic nonlinear spring in the tuned-inerter-damper device (see Zhang et al. [126]) results in the system shown in Fig. 5a. We call this a nonlinear energy sink-inerter of the TID type, or NESI-TID. Likewise, Zhang et al. [125] showed that the (non-grounded) tuned-mass-damper-inerter can be reconfigured with a nonlinear spring to give a nonlinear energy sink-inerter of the TMDI type (NESI-TMDI). Similarly, Javidialesaadi and Wierschem [42] showed that the grounded tuned-mass-damper-inerter can be reconfigured with a nonlinear spring to give a nonlinear energy sink inerter of the grounded TMDI type (NESIgTMDI).

Considering the equilibrium of mass $M$ in the NESITID system shown in Fig. 5a gives equations of motion of

$$
\begin{aligned}
M \ddot{x}+c \dot{x}+k x+c_{d}\left(\dot{x}-\dot{x}_{d}\right)+f_{d}\left(x-x_{d}\right) & =F(t), \\
\text { and } b \ddot{x}_{d}+c_{d}\left(\dot{x}_{d}-\dot{x}\right)+f_{d}\left(x_{d}-x\right) & =0 .
\end{aligned}
$$

Linear tuning rules are no longer applicable to these types of NESI systems. Therefore to obtain optimum parameters values for the nonlinear device, optimisation methods can be used as an alternative method.

An example of the response of the NESI-TID when subjected to a sine wave excitation force is shown in Fig. 5b. The NESI-TID system response (dot-dash line) is compared with the linear primary system response (blue solid line, similar to the primary system in Fig. 1), and a linear TID system response (dashed line). It should be noted that the parameters for Fig. 5 (b) have not been optimised directly. Instead, for the purpose of illustrating the concept, we have adapted the optimised parameters computed by Javidialesaadi and Wierschem [42] for a related grounded TMDI-type system (e.g. a NESI-gTMDI) subject to transient input signals. Despite this limitation, it can be seen in Fig. 5b that close to resonance the NESI-TID (dot-dash line) has the smallest displacement amplitude, when compared to the uncontrolled primary system (blue solid line), and a linear TID system response (dashed line).

In practice, the exact conditions for optimisation are dependent on the application being considered, and discussions regarding this type of optimisation can be found, for example in Javidialesaadi and Wierschem [42] or Wang et al. [110]. An alternative approach to direct optimisation is to carry out a harmonic balance analysis as a preliminary step before determining the optimum parameters, see for example Zhang et al. [126] or Wang et al. [112]. A comparative study of a negative 
(a)

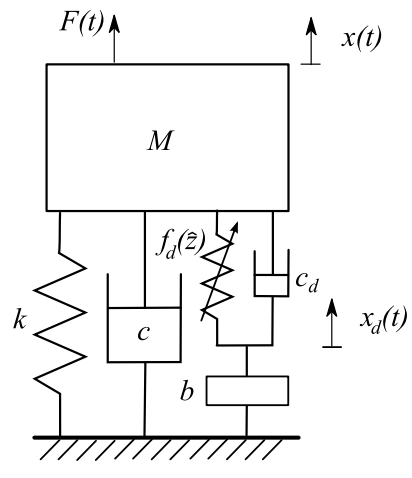

(b)

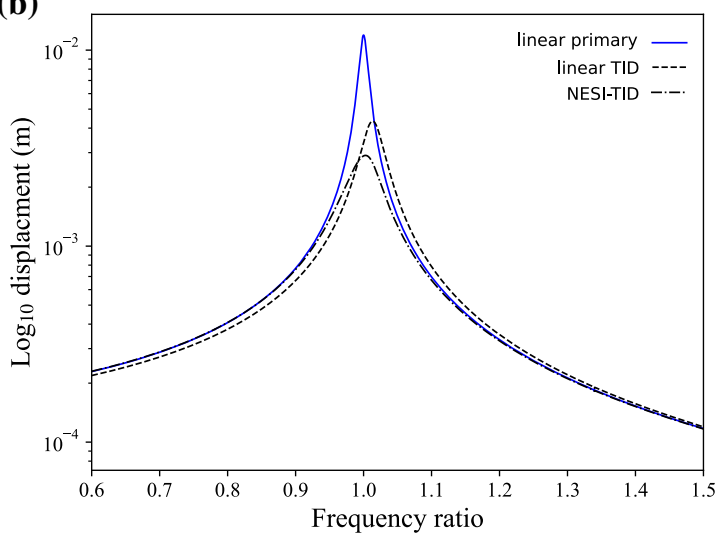

Fig. 5 Nonlinear energy sink inerter (NESI) example, showing a schematic diagram of a nonlinear energy sink inerter of the TID type (NESI-TID), where mass, $M$, is excited by force $F(t)$, and the TID spring has a nonlinear restoring force function, $f_{d}(\hat{z})$, where $\hat{z}=x-x_{d}$, b a simulation of the NESI-TID system (dot-dash line) compared with the linear primary system (blue solid line), and a linear TID system (dashed line). The following parameters were used; $M=10 \mathrm{~kg}, k=8500 \mathrm{~N} / \mathrm{m}$

stiffness damper and inerter damper was also carried out by Xiang et al. [117].

There is still the problem of how exactly the required nonlinear stiffnesses can be achieved in practice. To overcome this issue, several authors have recently studied the idea of combining quasi-zero stiffness mechanisms with inerters, see for example Wang et al.[110,112,113] and Yang et al. [118]. Note also that for civil engineering structures related negative stiffness concepts have been considered, as discussed by Luo et al. [65]. An example of this type of quasi-zero stiffness mechanism will be discussed in detail in the next section.

\subsection{Nonlinear inerter isolators}

Consider the vibration isolation example shown schematically in Fig. 6a. Here, the requirement is to isolate mass, $M$, from input $y(t)$. The response of the unisolated system with a linear spring and no inertance (similar to the primary system in Figs. 2 and 3) when excited with a sine wave is shown as the thick blue line in the transmissibility plot of Fig. 6d. There is a significant resonance peak that ideally should be reduced, along with the amplification region that can be reduced by moving the cross-over frequency to the left. The $c=5 \mathrm{~kg} / \mathrm{s}, b=12.15 \mathrm{~kg}$ and $F(t)=\sin (\Omega t) \mathrm{N}$. For the linear TID, the following parameters were used $c_{d}=7.7 \mathrm{~kg} / \mathrm{s}$, and $f_{d}=182\left(x-x_{d}\right)$ N. For the NESI-TID, the spring forces was given by $f_{d}=10^{7}\left(x-x_{d}\right)^{3} \mathrm{~N}$, and $c_{d}=10.0 \mathrm{~kg} / \mathrm{s}$. The frequency ratio is $\Omega / \omega_{p}$ where $\omega_{p}=\sqrt{k / M}$. Note that these parameters are adapted from the optimised parameters computed by Javidialesaadi and Wierschem [42], who computed optimal parameters for transient input signals rather than sine waves

effect of adding a linear inerter to the system, whilst keeping the linear spring, is shown as the dot-dashed line in the transmissibility plot of Fig. 6d. This has had the desired effects, and in addition has introduced an antiresonance (similar to the examples of Figs. 2 and 3 ), and in this case with an inertance to mass ration of $\mu=0.4$. Increasing $\mu$ is one way to continue to improve the isolation, but what about the situation when $\mu$ is already at the maximum possible value? Are there ways to improve the situation then?

One possibility is to use a nonlinear spring in combination with the inerter, as was done in the previous subsection. The example shown in Fig. $6 c$ is a quasizero nonlinear spring function based on the design method proposed by Shaw et al. [80], which can also be realised experimentally—see for example Alabuzhev [1], Shaw et al. [81] and Yang et al. [118]. The equation of motion for the nonlinear quasi-zero and inerter isolator in Fig. 6a can be written as

$(m+b) \ddot{z}+c \dot{z}+f(z)=-m \ddot{y}$,

where $z$ is the relative displacement $z=x-y$. Following the design method proposed by Shaw et al. [80] 


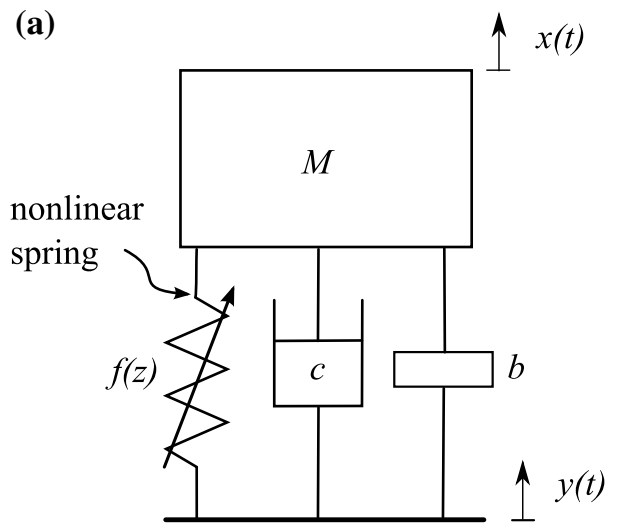

(c)

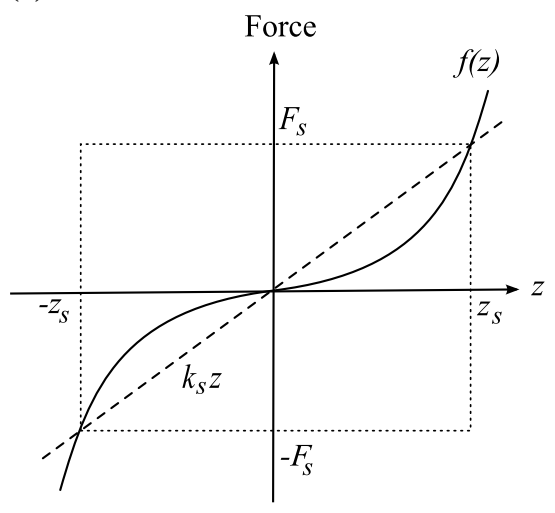

(b)

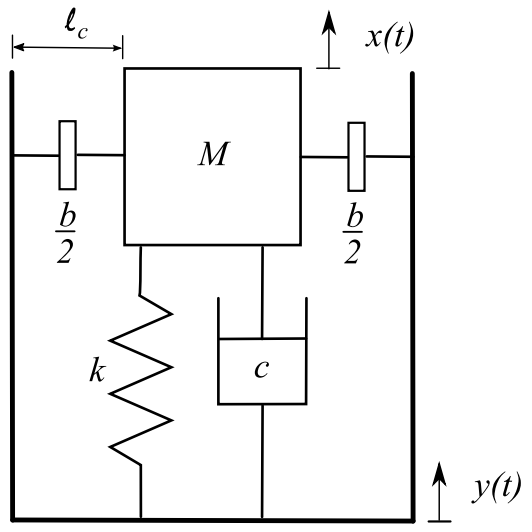

(d)

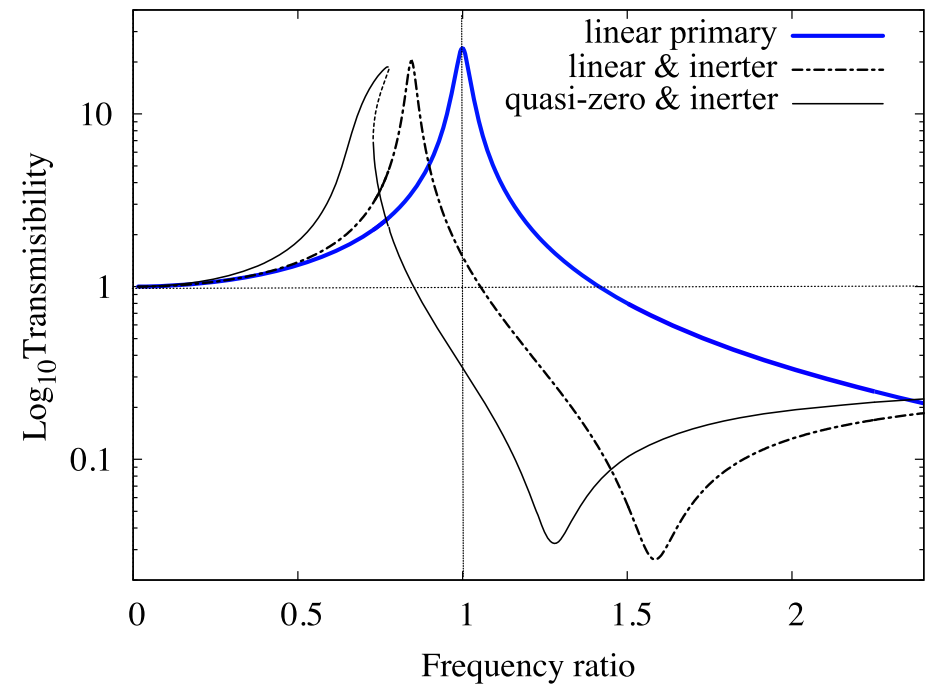

Fig. 6 Nonlinear inerter isolator example, showing a a schematic diagram of a nonlinear inerter isolator, where mass, $M$, is to be isolated from input $y(t)$, and the spring has a nonlinear restoring force function, $f(z)$, where $z=x-y$, b the geometrically nonlinear inerter isolator system proposed in de Haro Moraes et al. [19] and Wang et al. [115], c an example of a quasi-zero force function taken from Shaw et al. [80] where $F_{s}=M g$ is the static force due to gravity $g$, and $k_{s}$ is the equivalent linear stiffness, and $\mathbf{d}$ a comparison of linear- and nonlinearinerter isolators showing; the unisolated linear primary system

we define the nonlinear stiffness function as

$f(z)=k_{1} z+k_{3} z^{3}+k_{5} z^{5}$,

which is the solid curve shown in Fig. 6c. The stiffness values, $k_{1}$ and $k_{s}$ (see Fig. 6c) are predefined and then with $M=7.2 \mathrm{~kg}$, linear spring $k=80 \mathrm{~N} / \mathrm{m}, c=1.0 \mathrm{Ns} / \mathrm{m} \mathrm{sub}$ ject to a forcing of $y=0.04 \sin (\Omega t) \mathrm{m}$ and $b=0$ (thick blue line); the linear spring plus inerter case with the same parameters except inertance $b=2.9 \mathrm{~kg}$ so that $\mu=b / M=0.4$ (dot-dash line), and; the quasi-zero plus inerter case with the same parameters as the previous case except a nonlinear quasi-zero spring function designed using the method in Shaw et al. [80] with $k_{s}=52 \mathrm{~N} / \mathrm{m}$ and $\hat{z}_{r}=0.577$ is used (thin solid line). Note that the thin dashed line represents the part of the solution branch that is unstable

the nonlinear stiffness values are computed from

$$
\begin{aligned}
& k_{3}=\frac{F_{s}}{z_{s}^{3}}\left[\left(1-\frac{k_{1}}{k_{s}}\right) \frac{5 \hat{z}_{r}^{4}-1}{5 \hat{z}_{r}^{4}-3 \hat{z}_{r}^{2}}\right], \\
& \text { and } k_{5}=\frac{F_{s}}{z_{s}^{5}}\left[\left(1-\frac{k_{1}}{k_{s}}\right) \frac{1-3 \hat{z}_{r}^{2}}{5 \hat{z}_{r}^{4}-3 \hat{z}_{r}^{2}}\right]
\end{aligned}
$$


where $\hat{z}_{r}=z_{r} / z_{s}$ and $\pm \hat{z}_{r}$ defines the low stiffness range of the mount-see Shaw et al. [80] for further details.

The result of using this nonlinear quasi-zero and inerter isolator when excited with a sine wave is shown as the thin solid (and dashed) black line in the transmissibility plot of Fig. 6d. It can be seen, that for the same inertance values, using a quasi-zero spring instead of a linear spring has further improved the isolation effects when compared to the linear spring plus inerter case (dot dash line). Notice that the antiresonance is now closer to the position of the original resonance peak (although the transmissibility is slightly higher), and by further tuning the quasi-zero spring properties, it is possible to locate the antiresonance exactly at the original resonance position, thereby maximising the isolation benefit if operation is at resonance.

One of the potential drawbacks in using nonlinear spring functions is that the dynamic behaviour of the system is more complex. For example in Fig. 6d, there is a small section of dashed line, which represents the unstable solution branch for the quasi-zero and inerter isolator. Here, there will be saddle-node bifurcations, leading to jumps in the displacements as frequency is increased or decreased. Other undesirable, complex nonlinear behaviours may also be possible, and so careful design is required to avoid any unwanted effects.

Another method that can be used to introduce nonlinear behaviour in practice, is geometrically nonlinear arrangements of the device elements. For example, in Fig. 6b another type of the geometrically nonlinear inerter isolator system proposed in de Haro Moraes et al. [19] and Wang et al. [115] is shown, where the inerters are mounted horizontally, whilst the spring and damper are vertical.

A wider group of systems exhibiting this type of geometrically nonlinear arrangement of elements has recently been studied by Yang et al. [118]. In this study, the authors showed how the arrangements could be used to design specific transmissibility curves, by combining the geometrically nonlinear effect with a QZS-type spring system. There are multiple different other configurations that have been considered, and the interested reader can find recent examples in Zhang et al. [127] and Yang et al. [118], where it is noted that some systems can give the effect of combining isolation with absorption.

\subsection{Rocking structures and inerters}

In applications such as earthquake engineering, it is possible to have gravity-based structures that can rock when excited by a ground input motion. An example is shown in Fig. 7a where, following the classical analysis of Housner [35], a rectangular block of dimensions $2 H \times 2 B$ and mass, $M$, is able to rotate about points $O$ and $O^{\prime}$ when excited by the horizontal ground input acceleration, $a_{g}$. In the classical approach by Housner [35], inerters are not considered, but more recently the advantages of using rotational inertia for earthquake engineering applications have been studied by Makris and Kampas [67], ThiersMoggia and Málaga-Chuquitaype [97,98] and MálagaChuquitaype et al.[68]. The inerter(s) can be configured in a variety of locations, and the example shown schematically in Fig. 7a is chosen for simplicity in order to illustrate the concept.

In order to derive equations of motion for the block in Fig. 7a, we use the fact that the effective force on the block at point CG due to a ground acceleration $a_{g}$ is $f_{\text {eff }}=-m a_{g} R \cos (\alpha-\theta)$. Furthermore, the inerter is considered to be grounded at the left-hand end, and so the force across the inerter is $f_{I}=b \ddot{h}_{C G}$ where $\ddot{h}_{C G}$ is the horizontal acceleration of point CG. To compute this note that the tangential acceleration of point CG when the block is rotating about point $O$ is $R \ddot{\theta}$, so the horizontal component of this is $R \ddot{\theta} \cos (\alpha-\theta)$. As a result, $f_{I}=b \ddot{\theta} R \cos (\alpha-\theta)$ and the moment of this about the point $O$ is $b \ddot{\theta} R^{2} \cos ^{2}(\alpha-\theta)$. Now considering the moment equilibrium of the block in Fig. 7a around points $O$ and $O^{\prime}$, we obtain the following expressions governing their motion (see for example Thiers-Moggia and Málaga-Chuquitaype [97])

$$
\begin{aligned}
& \left(J_{b}+b R^{2} \cos ^{2}(\alpha-\theta)\right) \ddot{\theta}+M g R \sin (\alpha-\theta) \\
& \quad=-M a_{g} R \cos (\alpha-\theta), \theta>0 \\
& \left(J_{b}+b R^{2} \cos ^{2}(-\alpha-\theta)\right) \ddot{\theta}+M g R \sin (-\alpha-\theta) \\
& =-M a_{g} R \cos (-\alpha-\theta), \theta<0
\end{aligned}
$$

which can be combined into a single equation

$$
\begin{aligned}
& \left(J_{b}+b R^{2} \cos ^{2}(\alpha \operatorname{sgn}(\theta)-\theta)\right) \ddot{\theta}+M g R \\
& \sin (\alpha \operatorname{sgn}(\theta)-\theta)=-M a_{g} R \cos (\alpha \operatorname{sgn}(\theta)-\theta),
\end{aligned}
$$

where sgn denotes the signum function, and $J_{b}=$ $(4 / 3) M R^{2}$ is the moment of inertia of the block around the rotation points. 


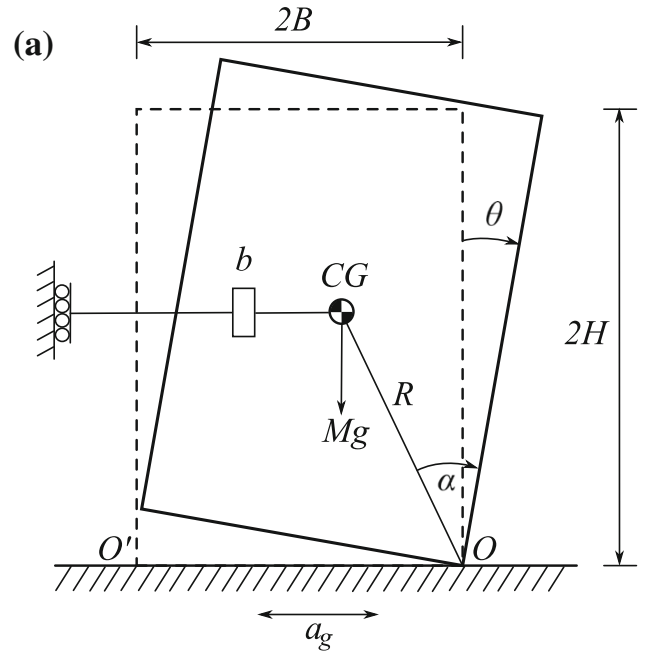

(c)

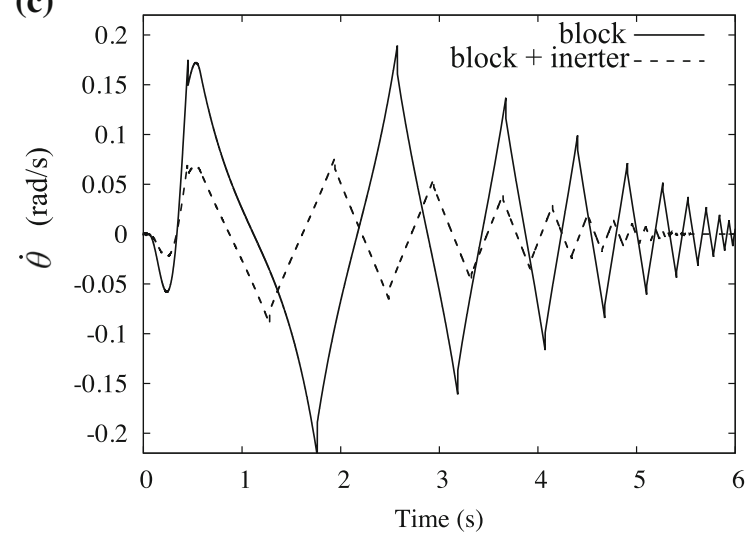

Fig. 7 Rocking block with inerter, showing a a schematic diagram of rocking block system, where the block with mass, $M$, is to be isolated from ground motion acceleration input $a_{g}$, and the block can rotate about points $O$ and $O^{\prime}$. The inerter is assumed to be grounded at the left-hand end, and has an inertance of $b$. The parameters $R=\sqrt{B^{2}+H^{2}}$ and $\alpha$ are used to define the slenderness of the block. b-d Simulation show-

The block is assumed not to slide in the horizontal direction at points $O$ and $O^{\prime}$, but impacts can occur when the block reaches the vertical position, when $\theta=$ 0 . The impact process is modelled using a coefficient of restitution, such that $\theta_{+}=r \theta_{-}$, where $\theta_{-}$is the angular velocity just before impact, and $\theta_{+}$is the velocity just after impact.

Combining Eq. (28) and the coefficient of restitution rule gives a nonlinear model for the rocking block with inerter system. For earthquake engineering applications, the primary interest relates to transient loads rather than steady-state response such as transmissibility's described in previous sections. An example of this (b)

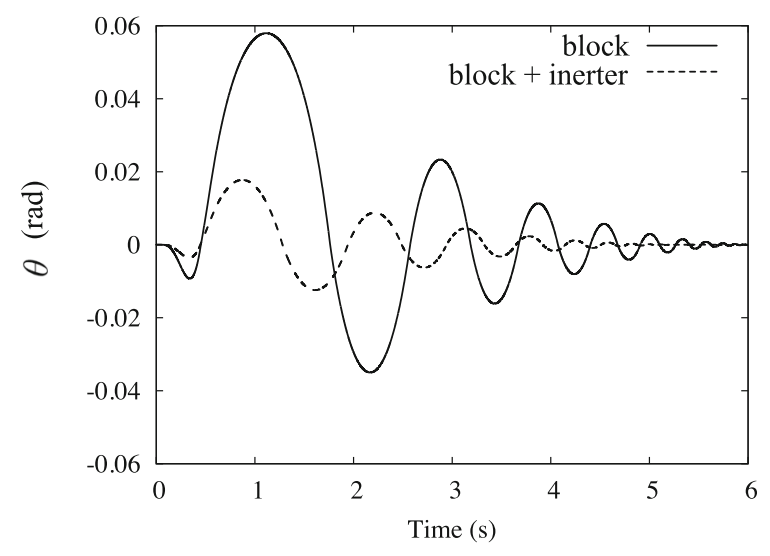

(d)

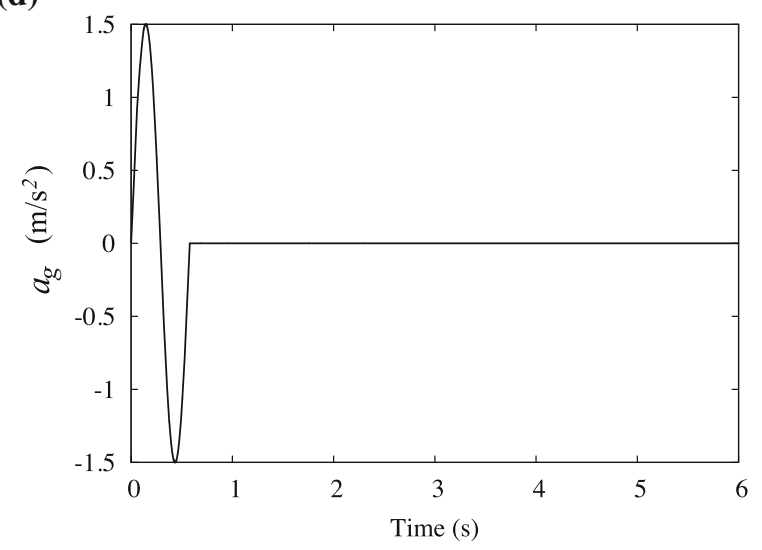

ing the angle of rotation (b) and angular velocity (c) of a block subjected to the sinusoidal impulse shown in (d). Parameter values are $\mu=b / M=0.5, R=1.0 \mathrm{~m}, \alpha=0.0873$ radians, $\Omega=10.85 \mathrm{rads} / \mathrm{s}, A_{g}=1.5 \mathrm{~m} / \mathrm{s}^{2}$. The acceleration input is below the level for overturning. See also Thiers-Moggia and MálagaChuquitaype [97] for further details and related results

type of situation is shown in Fig. 7d, where a single sine wave is used as a horizontal acceleration input for the rocking block with inerter system. The response to this input is shown in Fig. 7b, c, where the rotation angle $\theta$ is shown in (b) and the angular velocity $\dot{\theta}$ is shown in (c). In each of Fig. 7b, c, the solid line is the case where the block is simulated with no inerter (i.e. $b=0$ ) and the dashed line shows the case where the inerter is included. Clearly, there is a benefit in having the inerter included for the parameters selected for this example, as both $\theta$ and $\dot{\theta}$ are reduced in overall amplitude.

However, there are several further complexities of these types of systems. Firstly real earthquake inputs 
are more complex than the simple signal shown in Fig. $7 d$, and the amplitude can be large enough for the block to overturn. Determining the optimal inertance value is non-trivial, and the possibility of using clutched inerters can be advantageous in certain situations. Clutched inerters are nonlinear mechanisms that enable the inertance to be designed in a semi-active way-see $[55,56,58,67,68,97,98,108]$ and references therein for further details.

Other applications in earthquake engineering generally assume a linear inerter behaviour, but increasingly they are being considered in combination with nonlinear friction damping and/or nonlinear material properties, such as those used recently to model base isolation systems as recently shown, for example, by De Domenico and Ricciardi [17] and Zhao et al. [130].

\section{Conclusions and future directions for research}

In this paper, a review of the mechanical inerter, with a particular focus on the nonlinear dynamic behaviour has been presented. Although inerters are often modelled as a linear dynamic phenomenon, the physical devices that have been manufactured are typically nonlinear in nature. That said, linear models are often a reasonable approximation for a wide range of applications, although recent experimental tests (e.g. Pietrosanti et al. [75]) indicate the nonlinear nature of the response.

The historical context goes back to the development of isolators and absorbers in the first half of the twentieth century. Both mechanical and fluid-based nonlinear inerter devices were developed in the mid- and late twentieth century.

However, interest in the inerter really accelerated in the early 2000s following the work of Smith [87], who coined the term 'inerter' in the context of a forcecurrent analogy between electrical and mechanical networks. In particular work on ball-screw and rack-andpinion inerters developed strongly in this period, along with their use in the inerter-based devices such as, the tuned-viscous-mass-damper, tuned-inerter-damper and tuned-mass-damper-inerter.

Also important was the application of nonlinear inerter-based isolators and absorbers. These included different types of nonlinear energy sink inerters, nonlinear inerter isolators, and geometrically nonlinear inerter devices, many relying on quasi-zero-stiffness springs. In these devices, the nonlinear nature of the dynamics typically makes it difficult to determine the optimum parameter values required to minimise the unwanted vibration effects. As a result, optimisation is often used in order to design parameter values for the nonlinear inerter device.

Finally, in this review, rocking structures with inerters attached were considered. These types of applications arise in earthquake engineering where ground accelerations can cause blocks, and similar structural elements, to tip and rock back and forth. In this situation, it is the transient response that is of most interest, and attaching inerters has been shown to be effective in limiting rocking behaviour.

As with all reviews, there are limitations, and this review has only considered a selection of passive inerter devices. There are many other devices, particularly semi-active and active control applications that we have considered to be outside the scope of this review.

\subsection{Future directions for research}

It could be argued that the inerter is the most exciting development in the field of structural control since the patent of the tuned-mass-damper by Frahm in 1909 . Just like Frahm's idea, part of the appeal of the inerter is the simplicity of its governing equations, and subsequent tuning rules that allow engineers to design passive control systems. The nonlinear dynamics of the real manufactured inerter devices is something that has yet to be fully recognised and studied in depth. This is partly because the devices are often used in much larger scale systems where their nonlinear behaviour is less noticeable. A secondary reason is that there are far fewer studies that have experiments and/or real engineering applications, compared to those without. Other areas for future development are:

- There is considerably more scope in using nonlinear inerter models within the design of inerterbased devices such as nonlinear energy sinks. A recent example studied by Chen et al. [13] is applied to the problem of eliminating unwanted resonances from a composite plate. This type of multi-resonance analysis has significant potential for future research.

- Seeking forms of device that can be physically implemented and that exploit the benefits of nonlinear dynamics is an area of great interest. For example, this has been recently investigated for an energy 
harvesting application by Liu et al. [61], and for another application using nonlinear viscous damping by Huang et al. [40]. Building novel devices and device configurations is a related area of interest.

- Earthquake engineering offers some of the most challenging problems in dynamics due to the extreme nature of the loadings involved. More generally nonstationary stochastic inputs offer a related challenge, which has already been studied for the linear case $[6,43,70,95]$. Often the examples considered in earthquake engineering have to be quite idealised when compared to the real application. As a result, developing methods for transient responses such as earthquakes in the presence of nonlinear effects such as those discussed in this paper is an area for future development-see for example Radu et al. [76] and Ji et al. [44].

- Lastly, although semi-active and active control applications were not considered as part of this review, it should be mentioned that they offer some of the most interesting areas of development of future nonlinear inerter applications-see for example the following recent papers $[111,114,128$, 129] and references therein.

Acknowledgements The author would like to thank Hakan Dogan, Predaricka Deastra and Matthew Tipuric who gave comments on a draft version of the manuscript.

\section{Compliance with ethical standards}

Conflict of interest The author declares that he has no conflict of interest.

Informed consent No informed consent, or other ethical permission was required as part of this work.

Open Access This article is licensed under a Creative Commons Attribution 4.0 International License, which permits use, sharing, adaptation, distribution and reproduction in any medium or format, as long as you give appropriate credit to the original author(s) and the source, provide a link to the Creative Commons licence, and indicate if changes were made. The images or other third party material in this article are included in the article's Creative Commons licence, unless indicated otherwise in a credit line to the material. If material is not included in the article's Creative Commons licence and your intended use is not permitted by statutory regulation or exceeds the permitted use, you will need to obtain permission directly from the copyright holder. To view a copy of this licence, visit http://creativecommons.org/licenses/ by/4.0/.

\section{References}

1. Alabuzhev, P.M.: Vibration Protection and Measuring Systems with Quasi-Zero Stiffness. CRC Press, Boca Raton (1989)

2. Alujević, N., Čakmak, D., Wolf, H., Jokić, M.: Passive and active vibration isolation systems using inerter. J. Sound Vib. 418, 163-183 (2018)

3. Anderson, R.C., Smith, M.F.: A study of the kaman dynamic antiresonant vibration isolator. Technical report. Kaman Aerospace Corp., Bloomfield CT (1966)

4. Arakaki, T., Kuroda, H., Arima, F., Inoue, Y., Baba, K.: Development of seismic devices applied to ball screw: part 1 basic performance test of rd-series. AIJ J. Technol. Des. 5(8), 239-244 (1999). In Japanese

5. Arakaki, T., Kuroda, H., Arima, F., Inoue, Y., Baba, K.: Development of seismic devices applied to ball screw: part 2 performance test and evaluation of rd-series. AIJ J. Technol. Des. 5(9), 265-270 (1999)

6. Baduidana, M., Kenfack-Jiotsa, A.: Optimal design of inerter-based isolators minimizing the compliance and mobility transfer function versus harmonic and random ground acceleration excitation. J. Vib. Control 1077546320940175 (2020)

7. Bartlett, F.D., Flannelly, W.G.: Application of antiresonance theory to helicopters. J. Am. Helicopter Soc. 19(1), 11-15 (1974)

8. Biolek, D., Biolek, Z., Biolkova, V., Kolka, Z.: Nonlinear inerter in the light of Chua's table of higher-order electrical elements. In: 2016 IEEE Asia Pacific Conference on Circuits and Systems (APCCAS), pp. 617-620. IEEE (2016)

9. Biolek, Z., Biolek, D., Biolková, V., Kolka, Z.: Taxicab geometry in table of higher-order elements. Nonlinear Dyn. 98(1), 623-636 (2019)

10. Braun, D.: Development of antiresonance force isolators for helicopter vibration reduction. J. Am. Helicopter Soc. 27(4), 37-44 (1982)

11. Brock, J.E.: A note on the damped vibration absorber. Trans. ASME J. Appl. Mech. 13(4), 284 (1946)

12. Brzeski, P., Perlikowski, P.: Effects of play and inerter nonlinearities on the performance of tuned mass damper. Nonlinear Dyn. 88(2), 1027-1041 (2017)

13. Chen, H.Y., Mao, X.Y., Ding, H., Chen, L.Q.: Elimination of multimode resonances of composite plate by inertial nonlinear energy sinks. Mech. Syst. Signal Process. 135, 106383 (2020)

14. Chen, M.Z.Q., Hu, Y., Li, C., Chen, G.: Application of semi-active inerter in semi-active suspensions via force tracking. J. Vib. Acoust. 138(4), 041014 (2016)

15. De Domenico, D., Deastra, P., Ricciardi, G., Sims, N.D., Wagg, D.J.: Novel fluid inerter based tuned mass dampers for optimised structural control of base-isolated buildings. J. Franklin Inst. 356, 7626-7649 (2019)

16. De Domenico, D., Ricciardi, G.: An enhanced base isolation system equipped with optimal tuned mass damper inerter (TMDI). Earthq. Eng. Struct. Dyn. 47(5), 11691192 (2018)

17. De Domenico, D., Ricciardi, G.: Optimal design and seismic performance of tuned mass damper inerter (TMDI) for 
structures with nonlinear base isolation systems. Earthq. Eng. Struct. Dyn. 47(12), 2539-2560 (2018)

18. De Domenico, D., Ricciardi, G., Zhang, R.: Optimal design and seismic performance of tuned fluid inerter applied to structures with friction pendulum isolators. Soil Dy. Earthq. Eng. 132, 106099 (2020)

19. de Haro Moraes, F., Silveira, M., Goncalves, P.J.P.: On the dynamics of a vibration isolator with geometrically nonlinear inerter. Nonlinear Dyn. 93(3), 1325-1340 (2018)

20. Den Hartog, J.P.: Mechanical Vibrations. McGraw-Hill, New York (1934)

21. Desjardins, R.A., Hooper, W.E.: Antiresonant rotor isolation for vibration reduction. J. Am. Helicopter Soc. 25(3), 46-55 (1980)

22. Ding, H., Chen, L.Q.: Designs, analysis, and applications of nonlinear energy sinks. Nonlinear Dyn. 100(4), 30613107 (2020)

23. Dylejko, P.G., MacGillivray, I.R.: On the concept of a transmission absorber to suppress internal resonance. J. Sound Vib. 333(10), 2719-2734 (2014)

24. Evangelou, S., Limebeer, D.J., Sharp, R.S., Smith, M.C.: Steering compensation for high-performance motorcycles. In: 43rd IEEE Conference on Decision and Control, vol. 1, pp. 749-754. IEEE (2004)

25. Flannelly, W.G.: Dynamic antiresonant vibration isolator. US Patent 3,322,379 (1967)

26. Flower, W.C.: Understanding hydraulic mounts for improved vehicle noise, vibration and ride qualities. SAE Tech. Pap. 1, 850975 (1985)

27. Frahm, H.: Device for damping vibrations of bodies. US Patent US 989958 (1909)

28. Gartner, B.J., Smith, M.C.: Force-controlling hydraulic device. US Patent 8,881,876 (2014)

29. Giaralis, A., Taflanidis, A.A.: Optimal tuned mass-damperinerter (TMDI) design for seismically excited MDOF structures with model uncertainties based on reliability criteria. Struct. Control Health Monit. 25(2), e2082 (2018)

30. Golnaraghi, M.F., Nakhaie Jazar, G.: Development and analysis of a simplified nonlinear model of a hydraulic engine mount. J. Vib. Control 7(4), 495-526 (2001)

31. Gonzalez-Buelga, A., Lazar, I.F., Jiang, J.Z., Neild, S.A., Inman, D.J.: Assessing the effect of nonlinearities on the performance of a tuned inerter damper. Struct. Control Health Monit. 24(3), e1879 (2017)

32. Gutierrez Soto, M., Adeli, H.: Tuned mass dampers. Arch. Comput. Methods Eng. 20, 419-431 (2013)

33. Hashimoto, T., Fujita, K., Tsuji, M., Takewaki, I.: Innovative base-isolated building with large mass-ratio TMD at basement for greater earthquake resilience. Future Cities Environ. 1(1), 9 (2015)

34. Hessabi, R.M., Mercan, O.: Investigations of the application of gyro-mass dampers with various types of supplemental dampers for vibration control of building structures. Eng. Struct. 126, 174-186 (2016)

35. Housner, G.W.: The behavior of inverted pendulum structures during earthquakes. Bull. Seismol. Soc. Am. 53(2), 403-417 (1963)

36. Hu, Y., Chen, M.Z., Xu, S., Liu, Y.: Semiactive inerter and its application in adaptive tuned vibration absorbers. IEEE Trans. Control Syst. Technol. 25(1), 294-300 (2017)
37. Hu, Y., Chen, M.Z.Q., Shu, Z., Huang, L.: Analysis and optimisation for inerter-based isolators via fixed-point theory and algebraic solution. J. Sound Vib. 346, 17-36 (2015)

38. Hu, Y., Chen, M.Z.Q., Sun, Y.: Comfort-oriented vehicle suspension design with skyhook inerter configuration. J. Sound Vib. 405, 34-47 (2017)

39. Hu, Y., Wang, J., Chen, M.Z., Li, Z., Sun, Y.: Load mitigation for a barge-type floating offshore wind turbine via inerter-based passive structural control. Eng. Struct. 177, 198-209 (2018)

40. Huang, Z., Hua, X., Chen, Z., Niu, H.: Optimal design of TVMD with linear and nonlinear viscous damping for SDOF systems subjected to harmonic excitation. Struct. Control Health Monit. 26(10), e2413 (2019)

41. Ikago, K., Saito, K., Inoue, N.: Seismic control of singledegree-of-freedom structure using tuned viscous mass damper. Earthq. Eng. Struct. Dyn. 41(3), 453-474 (2012)

42. Javidialesaadi, A., Wierschem, N.E.: An inerter-enhanced nonlinear energy sink. Mech. Syst. Signal Process. 129, 449-454 (2019)

43. Javidialesaadi, A., Wierschem, N.E.: Response of a SDOF system with an inerter-based tuned mass damper subjected to non-stationary random excitation. In: Dynamics of Civil Structures, vol. 2, pp. 201-203. Springer (2020)

44. Ji, X., Cheng, Y., Hutt, C.M.: Seismic response of a tuned viscous mass damper (TVMD) coupled wall system. Eng. Struct. 225, 111252 (2020)

45. John, E.D.A., Wagg, D.J.: Design and testing of a frictionless mechanical inerter device using living-hinges. J. Franklin Inst. 356, 7650-7668 (2019)

46. Jones, R.: An analytical and model test research study on the kaman dynamic antiresonant vibration isolator (DAVI). Technical report. Kaman Aerospace Corp., Bloomfield, CT (1968)

47. Kawamata, S.: Development of a vibration control system of structures by means of mass pumps. Technical report. Institute of Industrial Science, University of Tokyo, Tokyo (1973)

48. Kawamata, S.: Control of structural vibration by inertia pump damper: part I theoretical model and response to harmonic excitation. In: Summaries of Technical Papers of Annual Meeting Architectural Institute of Japan (1986)

49. Kawamata, S.: Accelerated liquid mass damper and principles of structural vibration control. In: Structural Mechanics in Reactor Technology (1987)

50. Krenk, S., Høgsberg, J.: Tuned resonant mass or inerterbased absorbers: unified calibration with quasi-dynamic flexibility and inertia correction. Proc. R. Soc. A 472(2185), 20150718 (2016)

51. Kuhnert, W.M., Gonçalves, P.J.P., Ledezma-Ramirez, D.F., Brennan, M.J.: Inerter-like devices used for vibration isolation: a historical perspective. J. Franklin Inst. (2020)

52. Kuznetsov, A., Mammadov, M., Sultan, I., Hajilarov, E.: Optimization of improved suspension system with inerter device of the quarter-car model in vibration analysis. Arch. Appl. Mech. 81(10), 1427-1437 (2011)

53. Lazar, I.F., Neild, S.A., Wagg, D.J.: Using an inerter-based device for structural vibration suppression. Earthq. Eng. Struct. Dyn. 43(8), 1129-1147 (2014). https://doi.org/10. 1002/eqe. 2390 
54. Lazar, I.F., Neild, S.A., Wagg, D.J.: Vibration suppression of cables using tuned inerter dampers. Eng. Struct. 122, 62-71 (2016)

55. Lazarek, M., Brzeski, P., Perlikowski, P.: Design and identification of parameters of tuned mass damper with inerter which enables changes of inertance. Mech. Mach. Theory 119, 161-173 (2018)

56. Lazarek, M., Brzeski, P., Perlikowski, P.: Design and modeling of the cvt for adjustable inerter. J. Franklin Inst. 356(14), 7611-7625 (2019)

57. Lewis, T.D., Jiang, J.Z., Neild, S.A., Gong, C., Iwnicki, S.D.: Using an inerter-based suspension to improve both passenger comfort and track wear in railway vehicles. Vehicle Syst. Dyn. 58(3), 472-493 (2020)

58. Li, L., Liang, Q., Qin, H.: Equivalent linearization methods for a control system with clutching inerter damper. Appl. Sci. 9(4), 688 (2019)

59. Li, P., Lam, J., Cheung, K.C.: Control of vehicle suspension using an adaptive inerter. Proc. Inst. Mech. Eng. Part D J. Automob. Eng. 229(14), 1934-1943 (2015)

60. Liu, K., Liu, J.: The damped dynamic vibration absorbers: revisited and new result. J. Sound Vib. 284(3-5), 11811189 (2005)

61. Liu, M., Tai, W.C., Zuo, L.: Enhancing the performance of backpack energy harvester using nonlinear inerter-based two degrees of freedom design. Smart Mater. Struct. 29(2), 025007 (2020)

62. Liu, N., Li, C., Yin, C., Dong, X., Hua, H.: Application of a dynamic antiresonant vibration isolator to minimize the vibration transmission in underwater vehicles. J. Vib. Control 1077546317711538 (2017)

63. Liu, X., Jiang, J.Z., Titurus, B., Harrison, A.: Model identification methodology for fluid-based inerters. Mech. Syst. Signal Process. 106, 479-494 (2018)

64. Liu, X., Jiang, J.Z., Titurus, B., Harrison, A.J.L., McBryde, D.: Testing and modelling of the damping effects for fluidbased inerters. Proc. Eng. 199, 435-440 (2017)

65. Luo, H., Ikago, K., Chong, C., Keivan, A., Phillips, B.M.: Performance of low-frequency structures incorporated with rate-independent linear damping. Eng. Struct. 181, 324335 (2019)

66. Madhamshetty, K., Manimala, J.M.: Low-rate characterization of a mechanical inerter. Machines 6(3), 32 (2018)

67. Makris, N., Kampas, G.: Seismic protection of structures with supplemental rotational inertia. J. Eng. Mech. 142(11), 04016089 (2016)

68. Málaga-Chuquitaype, C., Menendez-Vicente, C., ThiersMoggia, R.: Experimental and numerical assessment of the seismic response of steel structures with clutched inerters. Soil Dyn. Earthq. Eng. 121, 200-211 (2019)

69. Marian, L., Giaralis, A.: Optimal design of a novel tuned mass-damper-inerter (TMDI) passive vibration control configuration for stochastically support-excited structural systems. Probab. Eng. Mech. 38, 156-164 (2014)

70. Masri, S.F., Caffrey, J.P.: Transient response of a SDOF system with an inerter to nonstationary stochastic excitation. J. Appl. Mech. 84(4) (2017)

71. O'connor, B.E.: Inertia controlled flutter damper. US Patent 2,742,113 (1956)

72. Okumura, A.: The gyro-mass inerter Japan patent koukai. h09-177875 (1997)
73. Papageorgiou, C., Houghton, N.E., Smith, M.C.: Experimental testing and analysis of inerter devices. J. Dyn. Syst. Meas. Contr. 131(1), 011001 (2009)

74. Pietrosanti, D., De Angelis, M., Basili, M.: Optimal design and performance evaluation of systems with tuned mass damper inerter (TMDI). Earthq. Eng. Struct. Dyn. 46(8), 1367-1388 (2017)

75. Pietrosanti, D., De Angelis, M., Giaralis, A.: Experimental study and numerical modeling of nonlinear dynamic response of SDOF system equipped with tuned mass damper inerter (TMDI) tested on shaking table under harmonic excitation. Int. J. Mech. Sci. 105762 (2020)

76. Radu, A., Lazar, I.F., Neild, S.A.: Performance-based seismic design of tuned inerter dampers. Struct. Control Health Monit. 26(5), e2346 (2019)

77. Rivin, E.I.: Passive Vibration Isolation. ASME Press, New York (2003)

78. Roberts, J.B., Spanos, P.D.: Random Vibration and Statistical Linearization. Courier Corporation, New York (2003)

79. Saitoh, M.: On the performance of gyro-mass devices for displacement mitigation in base isolation systems. Struct. Control Health Monit. 19(2), 246-259 (2012)

80. Shaw, A.D., Neild, S.A., Wagg, D.J.: Dynamic analysis of high static low dynamic stiffness vibration isolation mounts. J. Sound Vib. 332, 1437-1455 (2013)

81. Shaw, A.D., Neild, S.A., Wagg, D.J., Weaver, P.M., Carrella, A.: A nonlinear spring mechanism incorporating a bistable composite plate for vibration isolation. J. Sound Vib. 332(24), 6265-6275 (2013)

82. Shen, Y., Chen, L., Liu, Y., Zhang, X.: Modeling and optimization of vehicle suspension employing a nonlinear fluid inerter. Shock Vib. 2016 (2016)

83. Shen, Y., Chen, L., Liu, Y., Zhang, X.: Influence of fluid inerter nonlinearities on vehicle suspension performance. Adv. Mech. Eng. 9(11), 1687814017737257 (2017)

84. Siami, A., Cigada, A., Karimi, H.R., Zappa, E.: Vibration protection of a famous statue against ambient and earthquake excitation using a tuned inerter-damper. Machines 5(4), 33 (2017)

85. Siami, A., Karimi, H.R., Cigada, A., Zappa, E., Sabbioni, E.: Parameter optimization of an inerter-based isolator for passive vibration control of Michelangelo's Rondanini pietà. Mech. Syst. Signal Process. 98, 667-683 (2018)

86. Singh, R.: Dynamic design of automotive systems: Engine mounts and structural joints. Sadhana 25(3), 319-330 (2000)

87. Smith, M.C.: Synthesis of mechanical networks: the inerter. IEEE Trans. Autom. Control 47(10), 1648-1662 (2002)

88. Smith, M.C.: The inerter: a retrospective. Ann. Rev. Control Robot. Autonomous Syst. 3, 361-391 (2020)

89. Smith, M.C., Wang, F.C.: Performance benefits in passive vehicle suspensions employing inerters. Veh. Syst. Dyn. 42(4), 235-257 (2004)

90. Smith, N., Wagg, D.J.: A fluid inerter with variable inertance properties. In: Proceedings of the 6th European Conference on Structural Control, pp. 1-8 (2016). https://doi. org/10.15131/shef.data.4206096.v1

91. Soltani, P., Pinna, C., Wagg, D.J., Whear, R.: Ageing simulation of a hydraulic engine mount: a data-informed finite element approach. Proc. Inst. Mech. Eng. Part D J. Automob. Eng. 233(10), 2432-2442 (2018) 
92. Sugimura, Y., Goto, W., Tanizawa, H., Saito, K., Nimomiya, T.: Response control effect of steel building structure using tuned viscous mass damper. In: Proceedings of the 15th World Conference on Earthquake Engineering, pp. 24-28 (2012)

93. Sun, X.Q., Chen, L., Wang, S.H., Zhang, X.L., Yang, X.F.: Performance investigation of vehicle suspension system with nonlinear ball-screw inerter. Int. J. Automotive Technol. 17(3), 399-408 (2016)

94. Swift, S.J., Smith, M.C., Glover, A.R., Papageorgiou, C., Gartner, B., Houghton, N.E.: Design and modelling of a fluid inerter. Int. J. Control 86(11), 2035-2051 (2013)

95. Taflanidis, A.A., Giaralis, A., Patsialis, D.: Multi-objective optimal design of inerter-based vibration absorbers for earthquake protection of multi-storey building structures. J. Franklin Inst. 356(14), 7754-7784 (2019)

96. Takewaki, I., Murakami, S., Yoshitomi, S., Tsuji, M.: Fundamental mechanism of earthquake response reduction in building structures with inertial dampers. Struct. Control Health Monit. 19(6), 590-608 (2012)

97. Thiers-Moggia, R., Málaga-Chuquitaype, C.: Seismic protection of rocking structures with inerters. Earthq. Eng. Struct. Dyn. 48(5), 528-547 (2019)

98. Thiers-Moggia, R., Málaga-Chuquitaype, C.: Dynamic response of post-tensioned rocking structures with inerters. Int. J. Mech. Sci. 187, 105927 (2020)

99. Tipuric, M., Wagg, D., Sims, N.: Magnetorheological bypass valve design for a semi-active inerter. In: Active and Passive Smart Structures and Integrated Systems XII, vol. 10967, p. 109671L. International Society for Optics and Photonics (2019)

100. Titurus, B.: Generalized liquid-based damping device for passive vibration control. AIAA J. 56(10), 4134-4145 (2018)

101. Wagg, D., Pei, J.S.: Modeling a helical fluid inerter system with time-invariant mem-models. Struct. Control Health Monit. (2020)

102. Wang, F.C., Chan, H.A.: Vehicle suspensions with a mechatronic network strut. Veh. Syst. Dyn. 49(5), 811-830 (2011)

103. Wang, F.C., Hong, M.F., Chen, C.W.: Building suspensions with inerters. Proc. Inst. Mech. Eng. Part C J. Mech. Eng. Sci. 224(8), 1605-1616 (2010)

104. Wang, F.C., Hsieh, M.R., Chen, H.J.: Stability and performance analysis of a full-train system with inerters. Veh. Syst. Dyn. 50(4), 545-571 (2012)

105. Wang, F.C., Liao, M.K.: The lateral stability of train suspension systems employing inerters. Veh. Syst. Dyn. 48(5), 619-643 (2010)

106. Wang, F.C., Liao, M.K., Liao, B.H., Su, W.J., Chan, H.A.: The performance improvements of train suspension systems with mechanical networks employing inerters. Veh. Syst. Dyn. 47(7), 805-830 (2009)

107. Wang, F.C., Su, W.J.: Impact of inerter nonlinearities on vehicle suspension control. Veh. Syst. Dyn. 46(7), 575595 (2008)

108. Wang, M., Sun, F.: Displacement reduction effect and simplified evaluation method for SDOF systems using a clutching inerter damper. Earthq. Eng. Struct. Dyn. 47(7), 16511672 (2018)

109. Wang, R., Meng, X., Shi, D., Zhang, X., Chen, Y., Chen, L.: Design and test of vehicle suspension system with inerters.
Proc. Inst. Mech. Eng. Part C J. Mech. Eng. Sci. 228(15), 2684-2689 (2014)

110. Wang, X., He, T., Shen, Y., Shan, Y., Liu, X.: Parameters optimization and performance evaluation for the novel inerter-based dynamic vibration absorbers with negative stiffness. J. Sound Vib. 463, 114941 (2019)

111. Wang, Y., Ding, H., Chen, L.Q.: Averaging analysis on a semi-active inerter-based suspension system with relative-acceleration-relative-velocity control. J. Vib. Control 26(13-14), 1199-1215 (2020)

112. Wang, Y., Li, H.X., Cheng, C., Ding, H., Chen, L.Q.: Dynamic performance analysis of a mixed-connected inerter-based quasi-zero stiffness vibration isolator. Struct. Control Health Monit. 27(10), e2604 (2020)

113. Wang, Y., Li, H.X., Cheng, C., Ding, H., Chen, L.Q.: A nonlinear stiffness and nonlinear inertial vibration isolator. J. Vib. Control 1077546320940924 (2020)

114. Wang, Y., Meng, H., Zhang, B., Wang, R.: Analytical research on the dynamic performance of semi-active inerter-based vibration isolator with acceleration-velocitybased control strategy. Struct. Control Health Monit. 26(4), e2336 (2019)

115. Wang, Y., Wang, R., Meng, H., Zhang, B.: An investigation of the dynamic performance of lateral inerter-based vibration isolator with geometrical nonlinearity. Arch. Appl. Mech. 89(9), 1953-1972 (2019)

116. White Jr., L.: Theophilus redivivus. Technol. Culture 5(2), 224-233 (1964)

117. Xiang, S.H.I., Songye, Z.H.U.: A comparative study of vibration isolation performance using negative stiffness and inerter dampers. J. Franklin Inst. 356(14), 7922-7946 (2019)

118. Yang, J., Jiang, J.Z., Neild, S.A.: Dynamic analysis and performance evaluation of nonlinear inerter-based vibration isolators. Nonlinear Dyn. 99(3), 1823-1839 (2020)

119. Yilmaz, C., Kikuchi, N.: Analysis and design of passive band-stop filter-type vibration isolators for low-frequency applications. J. Sound Vib. 291(3-5), 1004-1028 (2006)

120. Zeng, Y.C., Ding, H., Du, R.H., Chen, L.Q.: A suspension system with quasi-zero stiffness characteristics and inerter nonlinear energy sink. J Vib. Control 1077546320972904 (2020)

121. Zhang, R., Zhao, Z., Pan, C., Ikago, K., Xue, S.: Damping enhancement principle of inerter system. Struct. Control Health Monit. 27(5), e2523 (2020)

122. Zhang, X.J., Ahmadian, M., Guo, K.H.: On the benefits of semi-active suspensions with inerters. Shock Vib. 19(3), 257-272 (2012)

123. Zhang, X.1., Gao, Q., Nie, J., : The mem-inerter: a new mechanical element with memory. Adv. Mech. Eng. 10(6), 1687814018778428 (2018)

124. Zhang, X.L., Geng, C., Nie, J.M., Gao, Q.: The missing mem-inerter and extended mem-dashpot found. Nonlinear Dyn. 101(2), 835-856 (2020)

125. Zhang, Y.W., Lu, Y.N., Zhang, W., Teng, Y.Y., Yang, H.X., Yang, T.Z., Chen, L.Q.: Nonlinear energy sink with inerter. Mech. Syst. Signal Process. 125, 52-64 (2019)

126. Zhang, Z., Lu, Z.Q., Ding, H., Chen, L.Q.: An inertial nonlinear energy sink. J. Sound Vib. 450, 199-213 (2019) 
127. Zhang, Z., Zhang, Y.W., Ding, H.: Vibration control combining nonlinear isolation and nonlinear absorption. Nonlinear Dyn. 1-19 (2020)

128. Zhao, G., Raze, G., Paknejad, A., Deraemaeker, A., Kerschen, G., Collette, C.: Active nonlinear energy sink using force feedback under transient regime. Nonlinear Dyn. 1$18(2020)$

129. Zhao, G., Raze, G., Paknejad, A., Deraemaeker, A., Kerschen, G., Collette, C.: Active nonlinear inerter damper for vibration mitigation of duffing oscillators. J. Sound Vib. 473, 115236 (2020)
130. Zhao, Z., Zhang, R., Jiang, Y., Pan, C.: Seismic response mitigation of structures with a friction pendulum inerter system. Eng. Struct. 193, 110-120 (2019)

Publisher's Note Springer Nature remains neutral with regard to jurisdictional claims in published maps and institutional affiliations. 